\title{
ANÁLISE ESTATÍSTICA DE PREÇOS AGRÍCOLAS DO BOI GORDO
}

\author{
ana Cláudia Piedade Sodero Kroll \\ Matemática
}

Orientador : Prof. Dr. JOAQUIM BENTO DE SOUZA FERREIRA FILHO

Dissertação apresentada à Escola Superior de Agricultura "Luiz de Queiroz", Universidade de São Paulo, para obtenção do título de Mestre em Ciências, Área de Concentração: Economia Aplicada.

P I R A C I C A B A

Estado de São Paulo - Brasil

Junho - 2001 


\title{
Dados Internacionais de Catalogação na Publicaçāo (CIP) DIVISĀO DE BIBLIOTECA E DOCUMENTAÇĀO - Campus "Luiz de Queiroz"/USP
}

\author{
Kroll, Ana Cláudia Piedade Sodero \\ Análise estatística de preços agrícolas do boi gordo / Ana Cláudia Piedade Sodero. - \\ - Piracicaba, 2001. \\ $80 p$ \\ Dissertaçăo (mestrado) - - Escola Superior de Agricultura Luiz de Queiroz, 2001. \\ Bibliografia.
}

1. Análise estatística 2. Bovino de corte 3. Preço agrícola I. Título

CDD 338.176213 
ANA CLÁUDIA PIEDADE SODERO KROLL.Análise Estatística de Preços Agrícolas.

p. item linha onde se lê leia-se

xiii resumo três

...em quatro municípios

... em quatro regiões

do estado de São

do estado de São

Paulo.

Paulo.

xiii resumo

nove

... referentes a janeiro

... referentes a

de 1998 a janeiro de

janeiro de 1998 a

$2000, \ldots$

dezembro de $1999, \ldots$

$\mathrm{XV} \quad$ summary seis

...known as cash chart. ...known as Box Plot.

xv summary sete e

...scoping January $1998 \quad$...scoping January

oito

through January $2000, \ldots$

1998 through

December $1999, \ldots$

$10 \quad 2.3$

terceira $\quad$...média $E(X)=\lambda \ldots$

...valor esperado

$$
E(X)=\lambda \ldots
$$

$23 \quad 3.3$

quinze

$\ldots Q_{1}+2 d Q \mathrm{e}$

$\ldots Q_{1}-2 d Q \mathrm{e}$

$C_{1}=Q_{1}+3 d Q, \ldots$

$C_{1}=Q_{1}-3 d Q, \ldots$

$50 \quad 5$

dois e

...em quatro municípios

...em quatro regiões

quatro do estado de São Paulo... do estado de São

Paulo...

...para cada município _...para cada região isoladamente,... isoladamente, ... 
HOMENAGEM SAUDOSA

Ao meu pai, Prof. Dr. Paulo Sodero Martins, extraordinário homem e pesquisador. A ele meu reconhecimento, pois seu exemplo e incentivo me levaram a esta conquista. 


\section{DEDICO}

À minha avó paterna Inah Maria;

À minha mãe Maria de Lourdes

Às minhas irmãs Ana Lúcia e Ana Elisa

\section{OFEREÇO}

Ao meu esposo Lúcio, grande companheiro.

Ao Lucas, nosso filho, incentivo maior para o término deste trabalho. 


\section{AGRADECIMENTOS}

Ao Professor Doutor Joaquim Bento de Souza Ferreira Filho, pelo profissionalismo, orientação e incentivo e, também, pela amizade e paciência durante o Mestrado.

Ao Departamento de Economia, Administração e Sociologia da Escola Superior de Agricultura "Luiz de Queiroz" (DEAS/ESALQ) da Universidade de São Paulo, pela chance de aprimoramento profissional.

Ao Professor Doutor Antonio Augusto Franco Garcia, pela atenção dispensada ao trabalho; pelo auxílio nos testes, análises estatísticas e interpretações e pelas valiosas sugestões.

Ao Professor Doutor Lúcio B. Kroll, pelo tempo dispensado à leitura e discussão do trabalho.

Ao Professor Doutor Carlos Tadeu dos Santos Dias, pelo auxílio, no início da pesquisa, nos testes estatísticos e interpretações.

Ao Professor Doutor Francisco Alberto Pino, pela colaboração e sugestões nas etapas iniciais deste trabalho.

Ao Centro de Pesquisa Avançada em Economia Aplicada, pela atenção e pronto fornecimento dos dados utilizados nesta pesquisa.

Aos Professores do DEAS, pelos muitos ensinamentos, amizade e convívio.

Aos funcionários do DEAS, em especial à Sra. Maria Aparecida Maieli Travalini, pela amizade e disposição em ajudar durante todo o curso. 
Ao Conselho Nacional de Pesquisa ( $\mathrm{CNPq}$ ), pelo auxílio financeiro concedido durante o curso de Mestrado.

À Lia Bueno Moretti pela tradução do resumo.

À Ligiana Clemente do Carmo, bibliotecária do DEAS, pela editoração nas referências bibliográficas.

À Helena Aparecida Cardoso pela editoração desta dissertação.

Aos Colegas do DEAS e a todos aqueles que colaboraram direta ou indiretamente para a realização deste trabalho. 


\section{SUMÁRIO}

Página

LISTA DE FIGURAS ix

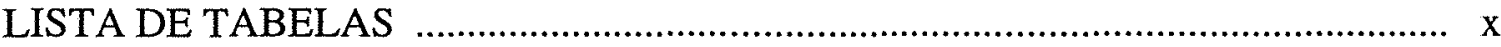

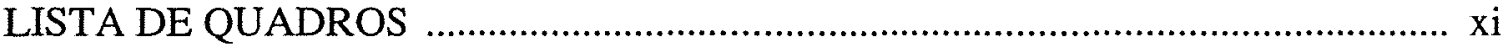

RESUMO

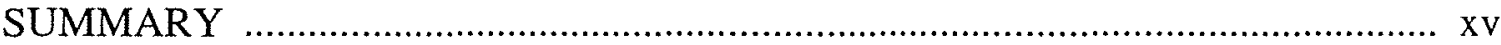

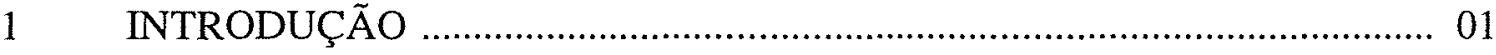

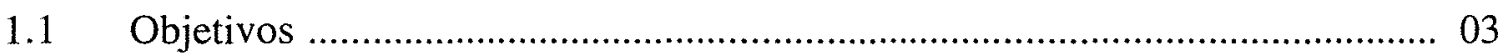

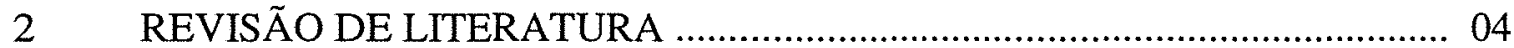

$2.1 \quad$ Boi Gordo ..................................................................................... 04

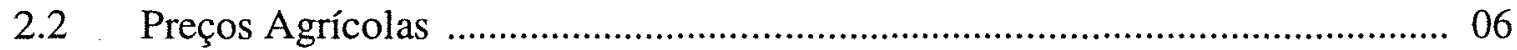

2.3 Distribuição Estatísticas de Preços ......................................................... 09

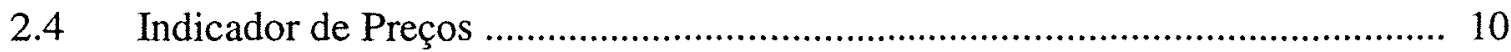

2.4.1 Cálculo do Indicador de Preços do Boi Gordo ......................................... 12

2.5 Distribuição Normal ................................................................... 13 


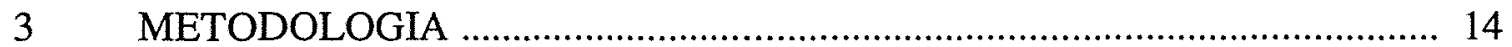

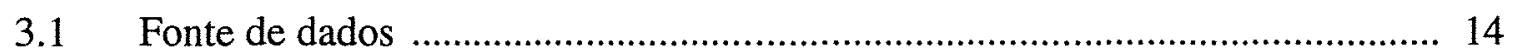

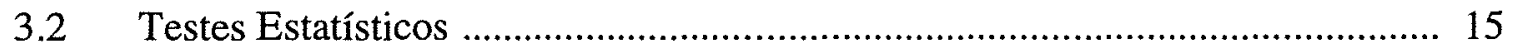

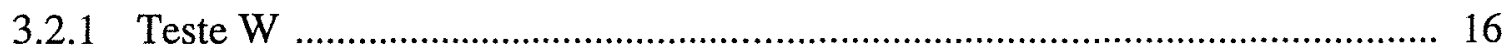

3.2.2 Teste de Kolmogorov-Smirnov ............................................................. 17

3.2.3 Teste de Lilliefors ……...................................................................... 19

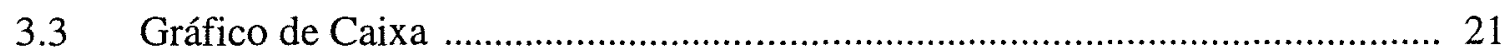

3.4 Medidas de Tendência Central ………………............................................24

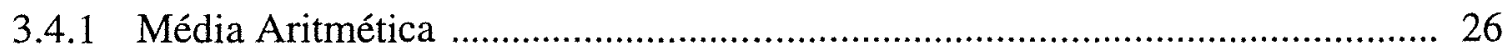

3.4.2 Média aritmética ponderada …................................................................ 27

3.4.3 Média geométrica …........................................................................... 27

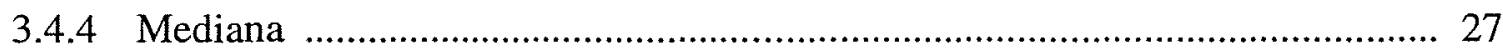

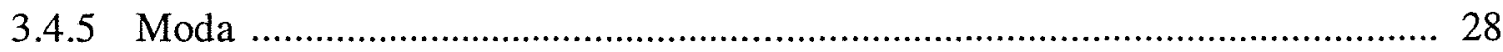

$4 \quad$ RESULTADOS E DISCUSSÃO …....................................................... 31

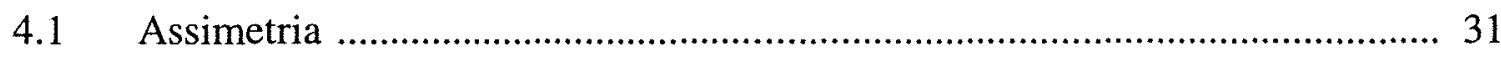

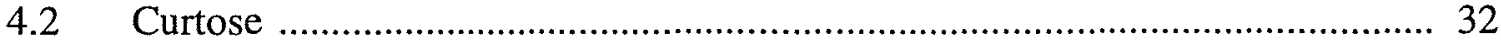

4.3 Medidas de Posição ..................................................................................... 34

4.4 Medidas de Dispersão ......................................................................... 35 
4.5 Testes Estatísticos para a normalidade

4.5.1 Teste W 36

4.5.2 Teste D 37

4.5.3 Teste de Lilliefors 38

4.6 Gráfico de Caixa . 41

4.7 Normal Plot 46

5 CONCLUSÕES 50

ANEXO 51

REFERÊNCIA BIBLIOGRÁFICA 59

BIBLIOGRAFIA RECOMENDADA 62 


\section{LISTA DE FIGURAS}

Página

1. Teste de Lilliefors para Araçatuba (1) ....................................................... 39

2. Teste de Lilliefors para Presidente Prudente (2) ..................................... 40

3. Teste Lilliefors para Bauru/Marília (2). ............................................. 41

4. Gráfico de Caixa para Araçatuba (1) .......................................................... 42

5. Gráfico de Caixa para Araçatuba (2) ...................................................... 43

6. Gráfico de Caixa para São José do Rio Preto (2) .................................... 44

7. Gráfico de Caixa para Bauru/Marília (2)............................................... 45

8. Gráfico de Caixa para Presidente Prudente (1). ............................................. 45

9. Normal Plot para Araçatuba (1) ........................................................... 47

10. Normal Plot para Araçatuba (2) ....................................................... 47

11. Normal Plot para São José do Rio Preto (2) ................................................ 48

12. Normal Plot para Bauru/Marília (1) ....................................................... 49

13. Teste Lilliefors para Bauru/Marília (1) ............................................. 53

14. Teste Lilliefors para Presidente Prudente (1) ........................................... 53

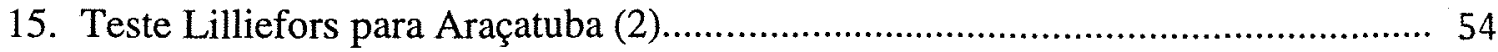

16. Teste Lilliefors para S. J. de Rio Preto (2)............................................. 54 
17. Gráfico de Caixa para São José do Rio Preto (1)

18. Gráfico de Caixa para Bauru/Marília (1).................................................. 55

19. Gráfico de Caixa para Presidente Prudente (2) ....................................... 56

20. Normal Plot para São José do Rio Preto (1) ................................................... $5 \bar{q}$

21. Normal Plot para Presidente Prudente (1)............................................... 57

22. Normal Plot para Presidente Prudente (2) .............................................. 58

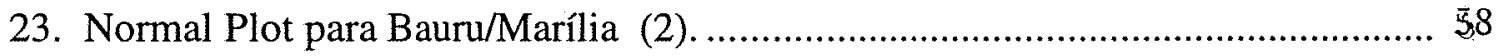




\section{LISTA DE TABELAS}

Página

1. Estatística Descritiva.

2. Medidas de Posição . 34

3. Medidas de Variabilidade 35

4. Testes Estatísticos para a Normalidade 37 


\section{LISTA DE QUADROS}

\section{Página}

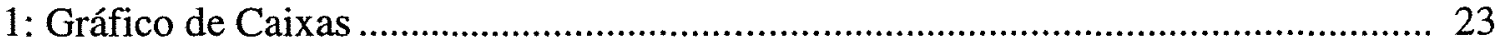




\title{
ANÁLISE ESTATÍSTICA DE PREÇOS AGRÍCOLAS DO BOI GORDO
}

\author{
Autora: ANA CLÁUDIA PIEDADE SODERO KROLL \\ Orientador: Prof. JOAQUIM BENTO DE SOUZA FERREIRA FILHO
}

\section{RESUMO}

O presente estudo foi elaborado com a finalidade de analisar as distribuições dos conjuntos de preços do Boi Gordo, utilizados no cálculo do Indicador do Boi Gordo (IBG) em quatro municípios do estado de São Paulo.

Para essas análises, ou seja, para o estudo das distribuições dos preços do Boi Gordo, foram utilizados três testes estatísticos: o teste W de Shapiro e Wilk, o teste de Kolmogorov-Smirnov e o teste de Lilliefors, além de um dispositivo gráfico conhecido como gráfico de caixa.

Os dados utilizados na pesquisa são os preços do Boi Gordo referentes a janeiro de 1998 a janeiro de 2000, fornecidos pelo Centro de Pesquisa Avançada em Economia Aplicada (CEPEA), da ESALQ/USP.

Através dos testes estatísticos e do gráfico de caixa, chega-se à conclusão de que realmente os preços não têm uma distribuição normal e, portanto, o uso da média como a medida de posição a representar os preços do boi gordo é incoerente.

Acredita-se que a solução ideal, seja a utilização da mediana como a medida de posição a representar esse preços, uma vez que é uma medida que representa de forma eficiente uma distribuição assimétrica, que é o caso das distribuições dos preços. 
Apesar de diferentes alternativas como solução para a não normalidade dos preços, o uso da mediana é a melhor opção, uma vez que representa de forma precisa uma distribuição assimétrica, além de ser uma medida bastante conhecida e de fácil cálculo. 


\title{
STATISTICAL ANALYSIS OF AGRICULTURAL PRICES OF BEEF CATTLE
}

\author{
Author: ANA CLÁUDIA PIEDADE SODERO KROLL \\ Adviser: Prof. JOAQUIM BENTO DE SOUZA FERREIRA FILHO
}

\section{SUMMARY}

The aim of this study was to analyze the distribution of beef cattle price sets used in the calculus of the Beef Cattle Indicator (IBG) in four countries of the state of Sào Paulo.

For these analyses, that is, for the study of the beef cattle price distributions, three statistical tests were used: Shapiro and Wilk's W test, the Kolmogorov-Smirnov test, and the Lilliefors test, in addition to a graphic device known as cash chart.

The data used in the research are the beef cattle prices scoping January 1998 through January 2000, provided by the Centro de Pesquisa Avançada em Economia Aplicada (CEPEA), of the ESALQ/USP.

Through the statistic tests and the cash chart one reaches the conclusion that the prices do not have a normal distribution so the use of the mean as the measure of the position representing the beef cattle prices is incoherent.

The ideal solution is believed to be the use of the median as the measure of the position representing these prices since it efficiently represents an asymmetric distribution, which is the case of the price distribution. 
Despite the different alternatives as a solution to the non normality of the prices, the use of the median is the best choice since it represents accurately an asymmetric distribution, besides being quite known and easily managed. 


\section{INTRODUÇÃO}

Grande parte da Estatística foi desenvolvida sob a suposição de normalidade das variáveis, o que permite o uso da média como medida adequada de tendência central. Entretanto, existem casos em que a suposição de que as variáveis seguem uma distribuição normal não é razoável, ou não encontra respaldo na realidade. Isso acontece com muitas variáveis econômicas, como no caso dos preços (Mandelbrot, 1963; Pino, 1990).

As estatísticas de preços estão entre as mais úteis em Economia, tanto para estudos, como para atuação no mercado. No entanto, segundo Pino et al. (2000), a variável preço não é tão simples quanto parece à primeira vista; a hipótese da distribuição normal para um conjunto de preços deve ser questionada uma vez que os preços são sempre positivos e que sua distribuição de freqüência costuma ser assimétrica.

No Brasil encontram-se várias entidades importantes, a maioria delas de natureza acadêmica, as quais coletam preços diariamente e processam esses dados com o fim de determinar índices de preços de diversas ordens. Muitas são as empresas que elaboram estudos a partir desses índices, mas, poucas são as que se preocupam com a maneira de como eles são obtidos.

Freqüentemente, profissionais de várias áreas de atuação como economistas, agentes de comercialização, administradores, engenheiros, sociólogos etc. envolvem-se em situações de análise, onde o interesse predominante concentra-se em medir possíveis 
diferenças entre grupos de dados em relação ao tempo e à localidades. Nesse sentido, o índice constitui um instrumento de análise poderoso.

Em termos gerais, um índice pode ser concebido como uma medida estatística destinada a comparar, através de uma expressão quantitativa global, grupos de variáveis relacionadas e com diferentes graus de importância. A obtenção de um índice resulta da combinação de variáveis, mediante uma medida de tendência central, geralmente a média.

O Centro de Estudos Avançados em Economia Aplicada (CEPEA), da ESALQ/USP, tem como uma de suas atividades o cálculo dos índices de preços de vários produtos agrícolas. Para isso, dados são levantados diariamente em regiões relevantes para a formação de preços, médias (aritmética ou ponderada) dos preços são calculadas e utilizadas como a medida de tendência central representativa da série.

O que ocorre, na realidade, é que a distribuição dos preços é suposta normal e, a partir daí, utiliza-se a média como medida de tendência central das variáveis. Entretanto, se a hipótese de normalidade dos preços agrícolas for rejeitada, o quanto isso estará influenciando e interferindo sobre os índices de preços? O quanto estará modificando esses resultados?

Pode-se então notar que a elaboração desses índices é um exercício constante de pesquisa e, sua utilização é essencial em muitos casos. Por isso, a preocupação em se realizar um trabalho visando o estudo das distribuições de preços agrícolas. Neste caso, a distribuição de preços agrícolas do Boi Gordo.

Sabe-se que, os índices calculados pelo CEPEA são aceitos pelo mercado, ou seja, seu grau de confiabilidade é grande; o que pretende-se aqui, é simplesmente um estudo mais detalhado; mais completo às considerações relevantes ao cálculo dos indicadores. Desta forma, a análise detalhada de distribuição estatística dos preços do boi gordo pode contribuir para o aprimoramento do processo. 


\subsection{Objetivos}

O objetivo geral deste trabalho é analisar a distribuição estatística dos preços do boi gordo no estado de São Paulo.

Pretende-se, inicialmente, analisar a distribuição de preços agrícolas através do Gráfico de caixa e através de três testes estatísticos: Teste W de Shapiro Wilk, Teste de Kolmogorov-Smirnov e Teste de Lilliefors. Os testes têm como propósito, testar a hipótese de normalidade das distribuições e o gráfico de caixa tem como objetivo, mostrar graficamente as distribuições.

Se a hipótese de normalidade for aceita, pode-se concluir então, que os preços agrícolas do boi gordo têm realmente uma distribuição normal e, que o uso da média como a medida de tendência central representativa do conjunto está correto. Caso contrário, deve-se buscar por uma solução; ou por uma medida de tendência central ou de posição que descreva e represente de maneira mais precisa a distribuição, ou então, por alguma das transformações que levem à normalização dos preços.

Para medidas cujas distribuições não são normais, uma simples transformação da escala de medida pode levar à normalidade. A raiz quadrada e o logaritmo são dois exemplos de transformações usadas freqüentemente. Para casos mais específicos, têm-se a família de transformações de Box e Cox, conhecida como Potência Ótima de Box-Cox.

Para finalizar o trabalho, pretende-se analisar a melhor medida de tendência central a representar a série. 


\section{REVISÃO DE LITERATURA}

\subsection{Boi Gordo}

Para estudar a formação dos preços da pecuária de corte o CEPEA/Revista Preços Agrícolas realizou uma atividade de coleta de informações no campo, tabulação e análise dos dados; definindo as categorias de animais, mapeando as principais regiões onde os preços são formados e, determinando os principais fatores das alterações nos preços (Zen, 1993).

Segundo Schouchana (1997), ao se estudar a formação do preço do boi gordo, verificou-se que o Estado de São Paulo é um local onde o número de compras e vendas de boi gordo é muito representativo, transparente e serve de referência para negócios em outros estados.

Os produtos agrícolas possuem características próprias e, portanto, exigem técnicas diferentes para a comercialização. Grãos, por exemplo, são volumosos, passíveis de serem estocados e fáceis de se manipular. Vegetais e frutas, por sua vez, são perecíveis e requerem empacotamento especial para transporte e estocagem. Produtos de origem animal requerem equipamento especial para transporte vivo e abate, processamento e transporte para o consumidor (Marques, 1993).

Segundo Marques (1993), os sistemas de comercialização da pecuária de corte, são caracterizados pelas variações cíclicas e estacionais de preços. As variações cíclicas de preços são provocadas, principalmente, pelo abate indiscriminado de matrizes no período de baixa de ciclo. Enquanto que a variação sazonal ou estacional que ocorre 
durante o ano, é provocada por efeitos climáticos que provocam variações na capacidade de suporte das pastagens. Esses dois efeitos (cíclico e sazonal) fazem com que os preços do setor apresentem grandes flutuações, com conseqüentes variações na renda agrícola e no nível de consumo da população.

A atividade de comercialização envolve a troca de bens e serviços por ativos monetários (geralmente dinheiro). Os termos ou a razão das trocas, os preços das mercadorias, geralmente são determinados pelo mercado no confronto entre a oferta e a demanda.

Quando o produto agrícola deixa a fazenda, ele se apresenta numa forma bruta, que precisa ser processada antes de ser revendida ao consumidor final. Esse processamento dependerá das características do produto e dos hábitos de consumo da população.

O grande volume ocupado pelos produtos agrícolas, principalmente por aqueles que apresentam maior proporção de água, acabam por encarecer o transporte e armazenamento desses produtos.

A produção agrícola encontra-se distribuída por diversas áreas, tornando necessário o serviço de transporte dentro das atividades de comercialização. Essa distribuição se dá, entre outros motivos, em função da disponibilidade dos fatores de produção, uma vez que os produtores de cada região procuram produzir produtos que lhes proporcionam maior rentabilidade.

Além das variações na quantidade, a qualidade dos produtos agrícolas também pode variar entre os anos (problemas climáticos ou fitossanitários). Essas variações são importantes porque o preço conseguido pelo produto no mercado depende, e muito, da sua qualidade, principalmente em regiões mais desenvolvidas (Marques, 1993). 
Segundo Zen (1999), a cadeia produtiva da carne bovina está dividida em três grandes grupos de análise. A produção do animal, o abate seguido do processamento da carne e a distribuição e o varejo. As três etapas têm um peso relativamente semelhante no processo produtivo, sendo diretamente responsáveis pelo preço e pela qualidade do produto final.

Segundo Zen (1999), a produção de carne está dispersa por praticamente todo o território nacional, mas a maior concentração está na região centro-sul do País. Os estados de Minas Gerais, Mato Grosso do Sul e Goiás dispõem dos maiores rebanhos, concentrando cerca de $38 \%$ do rebanho nacional. A distribuição dos animais por todos os estados da federação demonstra que a produção não está restrita a uma região ou estado. Isso deixa claro que a pecuária de corte não sofre restrições climáticas importantes em nenhuma região do país.

Segundo o mesmo autor, o Brasil, em termos de produtividade do rebanho pecuário possui resultados pouco animadores. Essa situação só será melhorada com a assimilação de novas técnicas de manejo por parte dos produtores. $\mathrm{O}$ meio de atingir esses níveis de produtividade é a adoção de métodos já bastante difundidos de manejo dos animais e das pastagens, ou seja, a atividade tem que deixar de ser extrativista e passar a ser profissionalizada.

\subsection{Preços Agrícolas}

Os estudos sobre preços de uma maneira geral, iniciaram-se por volta da década de sessenta mas, especificamente sobre a distribuição de preços agrícolas, objetivo deste trabalho, são escassos.

Pino et al. (2000), afirma que é preciso conhecer a distribuição de probabilidade dos preços antes de levantá-los para decidir que parâmetros estimar e que estimadores utilizar, uma vez que a variabilidade alta e um pequeno número de 
observações resultam em altos coeficientes de variação das estimativas, inviabilizando o uso de amostragem probabilística.

Mandelbrot (1963), trata da variação de certos preços especulativos, introduzindo um modelo de comportamento dos preços em um mercado especulativo. Para isso, utiliza-se da transformação logarítmica visando eliminar o problema da nãonormalidade.

As transformações mais conhecidas, como mencionado, são a raiz quadrada e a logarítmica, mas nem sempre são suficientes para a normalização. Algumas vezes torna-se necessário, a utilização de transformações mais específicas, como o da família de transformações de Box e Cox. Para se determinar qual das transformações poderá ser utilizada, é preciso estudar e analisar cada uma das séries de preços, caso a caso, pois cada uma delas poderá chegar à normalidade através de diferentes transformações.

Uma outra alternativa para o problema da não-normalidade, é a utilização de uma medida robusta de posição adequada que realmente descreva a série de preços. Utilizar a média para todas as séries de preços, ou seja, considerá-las distribuições normais pode levar à pequenas distorções.

Ainda em seu trabalho, Mandelbrot $(1963,1967)$, mostrou que a distribuição da variação de preços especulativos é mais pontiaguda que a normal, ou seja, é leptocúrtica e parece haver valores estranhos, aberrantes ou discrepantes, sendo mais apropriado o uso da distribuição exponencial dupla ou uma distribuição de variância infinita. Os valores discrepantes, aberrantes, conhecidos como outliers, entretanto, não devem ser esquecidos ou rejeitados, eles merecem tratamento especial; tirá-los da série, ou seja, eliminar esses valores pode levar a erros.

Tem-se verificado que realmente existe variabilidade muito alta entre preços dentro de um dado mês, dentro de uma semana e até mesmo dentro de um mesmo dia. E, segundo Pino et al.(2000), esses fatos não ocorrem para um ou outro produto isolado, mas para todos os produtos em todas as épocas do ano. 
O simples fato de um valor, nesse caso, de um preço, se encontrar afastado dos demais não indica por si só que é um valor mal observado ou errado, esse valor pode ser um valor correto. Portanto, não se deve eliminá-lo mas, sim, procurar saber o motivo de estar tão afastado.

Carlson (1975), preocupou-se em seu trabalho, em discutir a normalidade das expectativas de preços. Apesar dos Testes Qui-Quadrado indicarem que a normalidade não seria uma hipótese ruim, observou-se que as distribuições das amostras estavam distorcidas para a direita. Segundo o autor, outras distribuições foram testadas, como por exemplo, a lognormal, assimétrica à direita mas, os melhores ajustes foram obtidos com uma transformação de escala logarítmica.

É importante observar que ambos os autores, Pino et al.(2000) e Carlson (1975), encontraram melhores resultados ao empregar uma transformação logarítmica em sua amostra. Uma segunda observação, é em relação ao teste estatístico QuiQuadrado utilizado para testar a normalidade. Apesar de ser bastante conhecido por ser um dos mais antigos, sua eficiência em rejeitar a hipótese de normalidade tem sido comparada à de outros testes. Em seu trabalho Carlson (1975), pode perceber que o teste não foi suficientemente eficaz ao aceitar a hipótese de normalidade.

Pode-se verificar que todos os trabalhos onde se tratou uma série de preços, considerou-se uma outra distribuição que não a normal - distribuição exponencial- ou os dados passaram por uma transformação para serem normalizados ou então, foi sugerido a mediana ao invés da média, a medida de posição a representar a série.

O que não faltam são op̧̧ões para se trabalhar com os dados caso eles não tenham uma distribuição normal. O que não deve acontecer é a utilização dos dados, caso a hipótese de normalidade seja rejeitada, não se preocupando na realidade com a qualidade estatística dos dados envolvidos. 


\subsection{Distribuição de Preços}

Um estudo mais aprofundado das distribuições teóricas de preços agrícolas e de seus estimadores se faz necessário devido à importância e a utilidade das estatísticas de preços, uma vez que o tempo de acesso às informações de preços, bem como a capacidade de prever suas tendências, podem determinar a diferença entre lucro e prejuízo (Pino et al.,2000). Assim, é essencial se discutir qual o aspecto da distribuição teórica do preço de uma mercadoria ou serviço, ou seja, qual a distribuição de probabilidade que gerou um dado conjunto de preços.

Segundo Pino et al.(2000), algumas características estatísticas dos dados de preços devem ser discutidas, como a não normalidade. De fato, ele sugere em seu trabalho, o uso de distribuições do tipo exponencial, uma vez que a distribuição dos preços costuma ser assimétrica e os valores estranhos são relevantes de tal forma que em alguns casos, os dados de preços são mais bem descritos pela mediana ou a moda do que pela própria média.

Assim, a tentação de pensar na distribuição normal cai por terra quando lembramos que preços são sempre positivos e que a observação empírica mostra que sua distribuição de frequiência costuma ser assimétrica, com uma cauda mais longa à direita.

Mais ainda, quando uma variável é definida como a razão entre duas outras, sua distribuição pode ser razoavelmente complexa:

$$
P=\frac{V}{Q}
$$

onde $P$ pode representar o preço, $V$, o valor da transação e $Q$, a quantidade transacionada. $\mathrm{Ou}$, analogamente, poderiam estar representando a produtividade, a produção e a quantidade de um fator de produção, por exemplo, ou outra variável qualquer definida como a razão entre duas outras (Pino et al., 2000). 
Segundo o autor, se a distribuição teórica dos preços for do tipo exponencial,

$$
f(x)=\frac{1}{\lambda} e^{-\frac{x}{\lambda}}
$$

para $x>0$ e $\lambda>0$, então fará sentido calcular a média $E(X)=\lambda$ e a variância $V(X)=-\lambda^{2}$

De qualquer modo, outras medidas de tendência central, como moda e mediana, não coincidirão com a média, uma vez que a distribuição é assimétrica. Embora, estatisticamente, a média baste para descrever esse tipo de distribuição, é interessante estimar, também, as outras duas medidas. $\mathrm{Na}$ prática, pode ser mais interessante para um agente econômico conhecer a moda do preço do que sua média.

Em resumo, a discussão sobre a distribuição teórica dos preços serve para se definir qual parâmetro deve ser estimado e qual o grau de dificuldade para fazê-lo. Podese concluir, portanto, que a variável preço não é tão simples quanto parece à primeira vista, e que parece razoável estimar sua média, sua moda, sua mediana e sua variância; para que se possa comparar esses resultados e verificar qual dessas informações é realmente válida para descrever as distribuições de preços.

\section{4 Índices de Preços}

No Brasil, a experiência com mercados futuros remonta ao início do século XX, especificamente em 1917, quando foi fundada a primeira bolsa de commodities agrícolas, a Bolsa de Mercadorias de São Paulo - BMSP.

No início, a bolsa estava voltada fundamentalmente ao incentivo à produção, comercialização de bens, classificação de produtos. No ano seguinte, a mesma iniciou operações com futuros de algodão e, durante as décadas de 1970 e 1980, a BMSP lançou à negociação diversos contratos de commodities agropecuárias (Teixeira, 1992).

Em 1979, a bolsa de valores introduziu um novo conceito de negociação a futuro, com a criação do mercado futuro de ações individuais hoje existentes. O boi 
gordo, tem sido objeto de negociação em mercados futuros desde 1980, quando a BMSP, hoje fusionada com a Bolsa de Mercadorias \& Futuros - BM\&F; listou o produto entre os contratos da época.

Mas, foi somente em 1994, que decidiu-se contratar a elaboração de um índice de preços do mercado físico. Então, a partir de março de 1994 começou a ser divulgado o Indicador de Preço Disponível do Boi Gordo ESALQ/BM\&F, que serve como referência para a liquidação financeira dos contratos de boi gordo do mercado futuro da BM\&F (Frick, 1995).

O indicador de Preços do Boi Gordo ESALQ/BM\&F é um indicador diário do preço do Boi Gordo no estado de São Paulo. É uma média ponderada dos preços do boi gordo nas principais regiões produtoras do estado. O padrão do produto objeto da pesquisa atende às especificações do contrato futuro do Boi Gordo negociado na BM\&F.

A divulgação diária pela imprensa do Indicador de Preço Disponível do Boi Gordo ESALQ/BM\&F, como sinalizador para preços futuros e índice que definirá as liquidações financeiras, junto com a divulgação também diária dos preços praticados em negócios realizados na $\mathrm{BM} \& \mathrm{~F}$, torna o mercado físico do boi gordo democrático e transparente.

Segundo Shouchana (1997), para que o índice de preço calculado seja aceito pelo mercado, ele precisa necessariamente seguir quatro condições:

- Representar de forma apurada os preços correntes no mercado físico.

- Convergir de forma consistente para o preço físico no vencimento do contrato, diminuindo a variação e permitindo a previsibilidade da base.

- Evitar possibilidades de manipulação das informações que originarão o índice de preços. 
- Ser menor que a liquidação pela entrega física ou até mesmo, menor do que os custos de outras formas contratuais.

\subsubsection{Cálculo do Indicador de Preços do Boi Gordo}

Diariamente são coletadas as cotações em reais de preços praticados por arroba de boi gordo posto na fazenda; são levantadas também, junto a cada informante as escalas de abate, período transcorrido entre a contratação da compra final pelo frigorifico e sua efetiva realização e os prazos correntes de pagamento - que se inicia a partir do dia de abate.

Em seguida, os preços nominais são transformados em preços à vista mediante desconto, pelo prazo da transação - inclusive escala de abate - por intermédio da taxa média de Depósitos Interfinanceiros de um dia de prazo, referente ao dia útil anterior.

Obtém-se, depois, para cada região do Estado de São Paulo, a média aritmética de seus preços a vista, que representa o preço regional. A partir desses preços regionais, calcula-se a média ponderada, que corresponde ao preço médio à vista do Estado. O critério de ponderação utilizado, é o da importância de cada região na quantidade de abates sob controle do Serviço de Inspeção Federal. Para tanto, o peso atribuído a cada preço regional é atualizado mensalmente, correspondendo à média ponderada dos abates registrados em dado mês na região, nos últimos três anos, com ponderação maior para os anos mais recentes. Dessa forma, gera-se um painel dinâmico de ponderação, que permite captar a distribuição sazonal da atividade.

Finalmente, para fins de divulgação, o preço médio à vista do Estado é convertido em dólares dos Estados Unidos pela Taxa de Câmbio Referencial BM\&F.

Portanto, nos levantamentos de preços será coletado um conjunto de dados de preços nominais do boi gordo, em seguida esses preços serão transformados em preços à vista, calcula-se o preço regional através da média aritmética dos preços à vista, 
e finalmente obtém-se o preço médio do Estado de São Paulo - média aritmética ponderada pelas regiões.

\subsection{Distribuição Normal}

Todos os livros, em geral, de estatística, contêm um tópico sobre a Distribuição Normal e sua importância. A Distribuição Normal foi uma das primeiras a ser desenvolvida. E por ser conveniente para muitas pesquisas e pesquisadores, sua teoria tem sido desenvolvida desde então. Por ser relativamente fácil de se trabalhar, e por ser de grande importância em técnicas estatísticas que precisam da suposição de normalidade, métodos para se testar a normalidade de um conjunto de dados têm sido desenvolvidos.

É importante lembrar que uma média amostral pode possuir distribuição próxima a normal com um grande número de observações, mas isso não transforma a amostra, nem a população original da qual a amostra é obtida, em uma que possua distribuição normal (Shapiro, 1981). 


\section{MATERAL E MÉTODOS}

\subsection{Fonte dos Dados}

Os conjunto de dados utilizado para o trabalho foi o conjunto de preços diários do boi gordo, levantados pelo Centro de Estudos Avançados em Economia Aplicada (CEPEA) da ESALQ referentes a 1998 e 1999.

Esses dados são levantados diariamente nas principais regiões relevantes para a formação dos preços de cada produto. No caso do Boi Gordo, as praças (regiões de formações de preços) relevantes são Presidente Prudente, Araçatuba, Bauru/Marilia e São José do Rio Preto.

Nas análises, os conjuntos de dados foram divididos em dois períodos: (1) 1998 e (2) 1999. Assim, Araçatuba (1) é o conjunto de preços diários para o ano de 1998 e Araçatuba (2) é o conjunto de preços diários para o ano de 1999, e assim por diante.

Em cada uma dessas regiões são levantadas informações em grande número de fontes, através de diversos informantes; agentes são distribuídos na cadeia de comercialização da pecuária, dentre pecuaristas, corretores, frigoríficos e comerciantes de gado em geral.

Esses informantes são previamente contatados, por meio de entrevistas individuais com a equipe responsável pela elaboração do Indicador do Boi Gordo (IBG), e cadastrados como informantes. Novos informantes são permanentemente cadastrados, como forma de se acompanhar a dinâmica da comercialização. Para tanto, a equipe 
responsável pelo IBG se desloca constantemente para regiões de interesse, o que assegura a atualização da qualidade da informação.

No caso do Boi Gordo, as informações relevantes são os preços, os prazos de pagamento, as escalas de abate, e outras informações que sejam importantes para o acompanhamento do mercado.

\subsection{Testes Estatísticos}

Testes para hipóteses de distribuição em geral e para a normalidade em particular, têm sido uma das áreas de contínua pesquisa na estatística, tanto teórica quanto prática. Uma possibilidade para tal interesse é que muitos procedimentos estatísticos têm se baseado e derivado de hipóteses de distribuições particulares, especialmente as de normalidade (Snedecor, 1980).

Segundo Campos (1983), deve-se observar que muitas vezes a amostra não tem uma distribuição normal, mas pode-se verificar, através de testes estatísticos de normalidade, se seria razoável estudar os dados através da distribuição normal, quando as diferenças entre a função de distribuição normal e a verdadeira função de distribuição são insignificantes.

Provavelmente, o procedimento mais antigo para se testar hipóteses de distribuição seja o teste de Qui-Quadrado proposto por Karl Pearson em 1900. Mas o uso desse teste para se testar normalidade das distribuições, diminuiu nos últimos anos devido ao seu baixo poder em rejeitar um modelo quando este é incorreto (Shapiro, 1990). Portanto, para esse trabalho, foram escolhidos outros três testes mais poderosos, ou seja, testes que fornecem uma melhor chance de rejeição a modelos incorretos. Estes serão apresentados a seguir. 


\subsubsection{Teste W}

O teste W apresentado por Shapiro e Wilk (1965) é um procedimento eficiente para avaliar a suposição de normalidade de uma amostra contra um amplo espectro de alternativas não normais.

Inicia-se o teste ordenando as variáveis tal que $X_{1} \leq X_{2} \leq \ldots \leq X_{n}$ para uma amostra de tamanho $n$.

Em seguida calcula-se $S^{2}$, soma de quadrados dos desvios das observações em torno da média aritmética,

$$
S^{2}=\sum_{i=1}^{n}\left(X_{i}-\bar{X}\right)^{2}=\sum_{i=1}^{n} X_{i}^{2}-\frac{\left(\sum_{i=1}^{n} X_{i}\right)^{2}}{n}
$$

Calcula-se

$$
b=\sum_{i=1}^{k} a_{n-i+1}\left(X_{n-i+1}-X_{i}\right)
$$

onde $k=\frac{n}{2}$ se $n$ for par, enquanto $k=\frac{n-1}{2}$ se $n$ é impar, e os valores de $a_{n-i-1}$, para $i=1, \ldots, k$ são dados em uma tabela de coeficientes $\left\{a_{n-i-1}\right\}$ para o teste $\mathrm{W}^{1}$.

Calcula-se a estatística do teste

$$
\mathrm{W}=\frac{b^{2}}{S^{2}}
$$

1 Tabela dos coeficientes $\left\{a_{n-i-1}\right\}$ para o teste de normalidade retirada de Shapiro e Wilk (1965). 
Compara-se o valor de $\mathrm{W}$ calculado com os percentis da distribuição desta estatística mostrada em tabela ${ }^{2}$. Pequenos valores de $\mathrm{W}$ são significativos, isto é, indicam não normalidade. Consequentemente, se o valor de $\mathrm{W}$ calculado for menor do que o valor de $\mathrm{W}_{\alpha}$ tabelado, rejeita-se a hipótese de normalidade num teste de nível $\alpha$.

Como destaca Shapiro (1990), esse teste pode não ser tão eficiente quando lidamos com amostras grandes $(n \geq 50)$ mas, em compensação, para amostras menores, como é o caso, para o qual foi elaborado, ele é comparativamente sensível a uma alta gama de não normalidade e especialmente sensível à assimetria.

\subsubsection{Teste de Kolmogorov-Smirnov}

É um teste não-paramétrico, utilizado para se testar a hipótese de diversas distribuições, não só a de normalidade. O princípio deste teste baseia-se na comparação da curva da freqüência cumulativa dos dados, como função de distribuição teórica em hipótese. Quando as duas curvas se sobrepõem, a estatística do teste é calculada através da máxima diferença entre ambas. A magnitude da diferença estabelece-se probabilisticamente, segundo a lei de probabilidade dessa estatística, que se encontra tabelada. Se os dados experimentais se afastam significativamente do que é esperado segundo a distribuição em hipótese, então as curvas obtidas devem encontrar-se igualmente afastadas, e por um raciocínio análogo, se o ajustamento ao modelo hipotético é admissível, as curvas têm um delineamento próximo.

Segundo Campos (1983), esse teste foi desenvolvido para adaptação de uma específica e bem conhecida distribuição $F_{0}(X)$, a dados provenientes de uma distribuição desconhecida $F_{N}(X)$, ou seja, é um teste baseado na proximidade da função de distribuição empírica e a função de distribuição hipotética. $\left(F_{0}(X)\right.$ é a função de distribuição hipotética para a variável aleatória e $F_{N}(X)$ é a função empírica baseada na variável aleatória de tamanho $N$ ).

${ }^{2}$ Pontos de porcentagem para o teste $\mathrm{N}$ retirada de Shapiro-Wilk (1965). 
O teste de Kolmogorov-Smirnov para uma amostra, é um teste de aderência, isto é, diz respeito ao grau de concordância entre a distribuição de um conjunto de valores observados e determinada distribuição teórica específica. Determina se os valores da amostra podem razoavelmente ser considerados como provenientes de uma população como aquela da distribuição teórica (Siegel, 1975).

A vantagem do teste Kolmogorov-Smirnov, é que ele pode ser aplicado, sem restrição, para pequenas amostras. Além disso, trata as variáveis individualmente, não perdendo informações em decorrência de agrupamentos, como ocorre no caso do teste Qui-Quadrado (Siegel, 1975; Campos, 1983).

Considera-se $F_{0}(X)$ a distribuição de freqüência acumulada, teórica, sob $\mathrm{H}_{0}$, isto é, para qualquer valor de $\mathrm{X}$, o valor de $F_{0}(X)$ é a proporção de valores esperados menores ou iguais a $\mathrm{X}$ e $F_{N}(X)$ a distribuição de frequêencia acumulada de uma amostra aleatória de $N$ observações.

Pela hipótese de nulidade, de que a amostra tenha sido extraída da distribuição teórica especificada, neste caso $\mathrm{H}_{0}: F_{0}(X)$ tem distribuição normal, esperase que, para cada valor de $X, F_{N}(X)$ esteja suficientemente próximo de $F_{0}(X)$, ou seja, sob $\mathrm{H}_{0}$, espera-se que as diferenças entre $F_{N}(X)$ e $F_{0}(X)$ sejam pequenas e estejam dentro dos limites dos erros aleatórios. A prova de Kolmogorov-Smirnov focaliza a maior dessas diferenças. O maior valor de $F_{0}(X)-F_{N}(X)$ é chamado desvio absoluto, D:

$$
\mathrm{D}=\text { máximo }\left|F_{0}(X)-F_{N}(X)\right|
$$

Se $D \leq D_{n}$, valor crítico fornecido pela tabela ${ }^{3}$ que contêm os valores críticos de $\mathrm{D}$ na prova de Kolmogorov-Smirnov, aceita-se $\mathrm{H}_{0}$.

${ }^{3}$ Valores críticos de D para Prova $K-S$ retirada de Siegel (1975). 


\subsubsection{Teste de Lilliefors}

O teste de Lilliefors é uma adaptação do teste de Kolmogorov-Smirnov, usado para a verificação de normalidade de um conjunto de dados. A diferença básica entre os testes é que este testa a normalidade a partir de média e desvio fornecidos enquanto que o teste de Kolmogorov-Smirnov usa a média e o desvio-padrão, calculados no próprio conjunto de dados.

Lilliefors (1967), introduziu uma modificação no teste de KolmogorovSmirnov para se testar normalidade. Ele ampliou esse teste aos casos em que a média e variância não são especificadas, mas sim estimadas através dos dados da amostra.

$$
\begin{aligned}
& \hat{m}=\frac{\sum_{i=1}^{n} x_{i}}{n} \\
& s^{2}=\frac{\sum_{i=1}^{n}\left(x_{i}-\hat{m}\right)^{2}}{n-1}
\end{aligned}
$$

onde:

$\hat{m}$ é a estimativa da média,

$x_{i}$ é o valor da observação $i \operatorname{com} i=1,2, \ldots, i, \ldots, n$

$n$ é o tamanho da amostra.

E obtemos a variável reduzida

$$
z_{i}=\frac{x_{i}-\hat{m}}{s}, i=1,2, \ldots, n
$$


Conforme Campos (1983), o teste foi estruturado analogamente ao de Kolmogorov-Smirnov, a partir dos $z_{i}$, ao invés da variável original, ou seja, calcula-se

$$
\mathrm{D}=\sup \left|\mathrm{F}\left(\mathrm{z}_{i}\right)-\mathrm{S}\left(\mathrm{z}_{i}\right)\right|
$$

Compara-se o valor calculado D com o valor da tabela ${ }^{4}$ que contêm os valores críticos da estatística $D$ para o Teste de Lilliefors e rejeita-se a hipótese de normalidade quando o valor de $\mathrm{D}$ exceder o valor crítico dado na tabela .

Mas deve-se observar que, uma vez que a média e a variância foram estimadas através da amostra, os limites superiores da distribuição $\mathrm{D}$ do teste de Kolmogorov-Smirnov não são apropriados. Tem-se uma tabela específica contendo os valores para o teste de Lilliefors.

Portanto, a aceitação de $\mathrm{H}_{0}$ não significa que a distribuição padrão seja normal, mas apenas nos indica que esta é uma razoável aproximação da distribuição desconhecida.

Em seu artigo, Stephens (1974) descreve o teste qui-quadrado como um teste clássico, com certas vantagens como por exemplo, ser bem adaptado para o caso em que a função de distribuição $\mathrm{F}(\mathrm{x})$ é descontínua, mas, na realidade, em seu trabalho, ele se preocupa em discutir testes baseados na função de distribuição empírica, por considerálos mais poderosos, ou seja, mais eficientes na hora de rejeitar a hipótese nula.

Entre eles, o teste D de Kolmogov-Smirnov, que ele compara com o teste W de Shapiro-Wilk. Segundo Stephens (1974), sobre o ponto de vista prático, o teste W tem algumas desvantagens; é limitado para $\mathrm{n} \leq 50$, uma vez que os coeficientes para a estimação de $S^{2}$ são dados para $\mathrm{n} \leq 20$ e valores aproximados são dados para $20<\mathrm{n} \leq$ 50 .

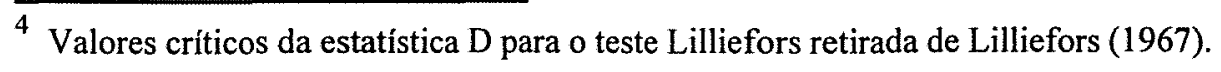


Em seu artigo, cita ainda alguns trabalhos realizados sobre o poder de algumas estatísticas, entre elas o de Qui-quadrado e o W de Shapiro-Wilk. Verificou-se que em geral, o teste Qui-quadrado é muito inferior ao teste W.

\subsection{Gráfico de Caixa}

O significado de um conjunto de dados, muitas vezes, só é compreendido ou visualizado quando esses dados vêm apresentados de forma eficiente. Uma das formas mais eficientes de apresentação de dados é através de gráficos. Eles oferecem uma visão mais rápida e fácil, porém detalhada a respeito das variáveis às quais se referem os dados.

O gráfico de caixa é um dispositivo gráfico para o resumo dos cinco pontosmediana, primeiro quartil, terceiro quartil, limite inferior e limite superior- procedimento que utiliza a mediana e os quartis para descrever os dados de forma eficiente.

Uma distribuição pode ser dividida em duas partes iguais através da mediana. Ela poderá ainda ser subdividida em quatro, em dez ou em cem partes iguais, originando os quartis, os decis e os percentis.

Os quartis $\mathrm{Q}_{1}, \mathrm{Q}_{2}, \mathrm{Q}_{3}$, dividem as observações ordenadas em ordem crescente, em quatro partes com número de dados iguais. A grosso modo, $\mathrm{Q}_{1}$ é o valor da observação que está a um quarto na fila de ordenação, $Q_{2}$ é a mediana e, $Q_{3}$ é a observação que está a três quartos na fila de ordenação.

Frigge et al. (1989), discute esse procedimento gráfico introduzido por John W. Tukey em 1970 em detalhes; mostrando que os gráficos podem variar no formato e no número de observações identificadas como outliers.

A partir desse gráfico, torna-se fácil identificar os outliers, que segundo Triola (1999), são valores extremamente raros, no sentido de que estão muito afastados da maioria. Ao explorar um conjunto de dados, não se pode deixar de considerar os 
outliers, uma vez que eles podem revelar informações tanto interessantes quanto importantes.

Esse gráfico é um procedimento muito simples, no entanto, apresenta um detalhamento importante para o trabalho, uma vez que capta as propriedades de tendência central, assimetria, dispersão e curtose, ou seja, resume um conjunto de dados exibindo diversas características.

O fato de não utilizar todos os valores da distribuição, pode muitas vezes ser vantajoso, em termos de economia de cálculo e principalmente, da influência de dados discrepantes.

O uso do resumo de cinco pontos através do gráfico de caixa, visa descrever de forma eficiente a série de dados. Os cinco pontos são: a mediana $(m d)$, o $1^{\circ}$ quartil $Q_{1}$ , o $3^{\circ}$ quartil $Q_{3}$, o limite inferior $(l)$ e o limite superior $(L)$.

O cálculo dos quartis é feito de modo semelhante ao da mediana. Para dados não agrupados, tem-se,

$$
\begin{aligned}
& \text { Para }_{n} \text { par } \\
& Q_{1}=\frac{n+2}{4} ; \quad Q_{2}=\frac{2 n+2}{4} ; \quad Q_{3}=\frac{3 n+2}{4} \\
& \text { Para } n \text { ímpar } \\
& Q_{1}=\frac{n+1}{4} ; \quad Q_{2}=\frac{2(n+1)}{4} ; \quad Q_{3}=\frac{3(n+1)}{4}
\end{aligned}
$$

Quando os dados estiverem dispostos em distribuições de freqüências, utiliza-se os limites inferiores das classes e as freqüências acumuladas que contêm os quartis $Q_{1}, Q_{2}$ e $Q_{3}$, respectivamente. 


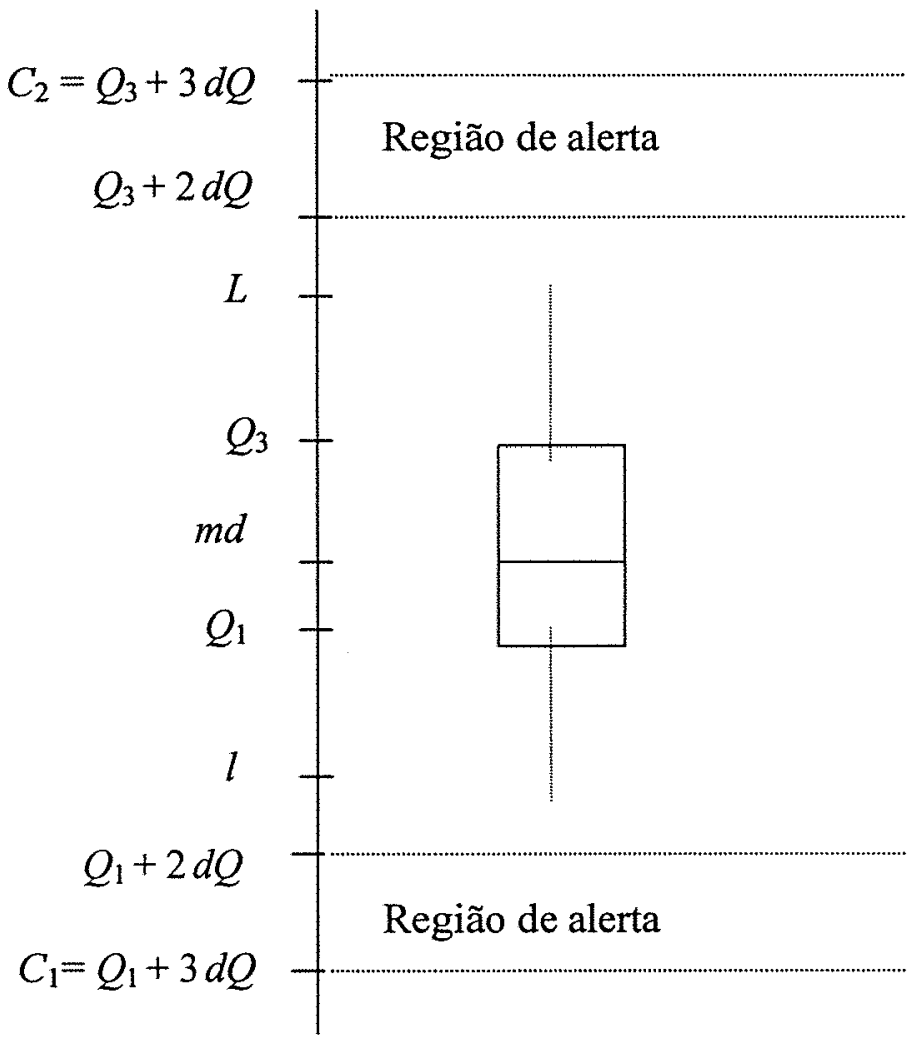

Quadro 1: Gráfico de Caixas.

onde, $m d$ é a mediana e $d Q=\frac{Q_{3}-Q_{1}}{2}$, provem de uma caixa retangular que localiza o centro do conjunto de dados. A linha vertical que corta a caixa mostra a posição de um típico valor central, a mediana.

E, da caixa retangular, partem duas linhas tracejadas que se estendem até os valores $l$ e $L$, tendo como limites $Q_{1}+2 d Q$ e $Q_{3}+2 d Q$, respectivamente. As observações que estão na região de alerta, devem ser vistas com cautela, pois estão distantes dos limites, mas, não tão distantes o suficiente, para serem consideradas outliers.

Por sua vez, os valores externos à região crítica, podem ser considerados valores discrepantes e, portanto, nenhuma análise estatística deve ser feita sem que eles sejam muito bem estudados. 
O gráfico de caixas, é extremamente explicativo, uma vez que apresenta as informações de cada distribuição, identificando valores importantes e mostrando a posição dos outliers.

Segundo Frigge et al. (1989), os quartis têm uma importancia extra uma vez que são a base para os limites e para a identificação dos outliers e portanto, a escolha da definição dos quartis pode afetar o número de observações fora da caixa, ou seja, o número de observações na região de alerta e o número de outliers.

\subsection{Medidas de Tendência Central}

A parte final do trabalho, visa apresentar as medidas de tendência central mais conhecidas e utilizadas, para que se possa escolher uma medida a ser usada para representar a série de preços agrícolas do Boi Gordo.

As medidas de tendência central são medidas numéricas que dão o valor central de uma distribuição de freqüência, proporcionando a descrição das características principais do conjunto de dados. Elas têm como objetivo, representar o ponto de equilíbrio ou o centro de uma distribuição.

Uma medida de tendência central de um conjunto de dados, mostra o valor em torno do qual se agrupam as observações. Ela permite caracterizar de maneira bastante concisa, um conjunto de dados.

A média (média aritmética) é a medida de tendência central mais usada. Mas é preciso estar atento ao caso em que forem encontrados "outliers" (valores extremos) no conjunto de dados, pois a média é muito sensível a esses valores e, devido a esse fato, algumas vezes outras medidas de tendência central são mais adequadas, ou sejam, dão um valor mais preciso ao conjunto de dados.

Uma média é um valor típico ou representativo de um conjunto de dados. Como esses valores típicos tendem a se localizar em um ponto central de um conjunto de 
dados ordenados segundo suas grandezas, as médias também são denominadas medidas de tendência central.

Os motivos que levam o pesquisador a procurar uma visão sintética de uma série de dados estatísticos podem ser diferentes; diferentes motivos, levam a uma ou outra medida mais conveniente. A escolha da medida depende da natureza da distribuição e do objetivo para o qual a média é calculada. Portanto, a escolha de uma ou mais dentre as diferentes medidas de tendência central depende dos objetivos fixados e, do enfoque da análise.

As principais medidas de tendência central são a média aritmética (ou, abreviadamente, a média), a mediana e a moda. Também são bastante utilizadas a média ponderada e a média geométrica. Cada uma delas apresenta vantagens e desvantagens, dependendo dos dados e dos fins desejados.

Em situações em que, ao obter ou analisar um conjunto de dados, forem encontrados um ou mais valores que aparentemente diferem razoavelmente dos outros, é preciso um tratamento especial. Esses valores produzem por vezes, dependendo da amplitude do seu afastamento, conclusões errôneas e distorções de parâmetros. As suas causas podem ser variadas, erros humanos ou instrumentais, ou outro tipo de situações análogas. Da sua identificação depende muitas vezes a validade das conclusões que são obtidas e, portanto, torna-se evidente o cuidado que se deve ter quanto à decisão de eliminar ou não esses valores, devendo sempre ser fundamental a opção tomada.

Convém frisar ainda que ao eliminar estes valores, pode-se, igualmente incorrer num erro, como por exemplo, sobrestimar a precisão dos dados, ou aceitar um modelo que não seja válido. O simples fato de um valor se encontrar afastado dos demais não indica por si só que é um valor mal observado ou errado, esse valor pode ser um valor correto e, eliminá-lo pode vir a ser um erro. 


\subsubsection{Média aritmética}

A média aritmética de um conjunto de $N$ números $X_{1}, X_{2}, X_{3} \ldots X_{N}$ é representada por $\bar{X}$ e definida por

$$
\bar{X}=\frac{X_{1}+X_{2}+X_{3}+\ldots+X_{i}+\ldots+X_{N}}{N}=\frac{1}{N} \sum_{i=1}^{N} X_{i}
$$

$\operatorname{com}_{i}=1,2,3, \cdots N$.

Considerada o parâmetro mais conhecido e utilizado na estatística básica devido à simplicidade de sua obtenção numérica e de sua interpretação. Suas propriedades matemáticas permitem sua utilização tanto em problemas teóricos quanto práticos.

Apesar da média apresentar excelentes propriedades que a mantêm como uma das medidas mais importantes em estatísticas, em certos casos ela pode não ser a medida de tendência central mais adequada para descrever ou caracterizar um conjunto de dados. Isto pode ocorrer, entre outros casos, quando existem dados extremos ou discrepantes (Iemma, 1992).

No cálculo da média participam todos os valores observados e assim, valores discrepantes dentro desse conjunto tendem a exercer influência desproporcional sobre a média. Como ela é o ponto de equilíbrio de uma distribuição de dados, isso faz dela, uma medida descritiva tão eficiente quanto mais simétrica for a distribuição das observações ao seu redor. 


\subsubsection{Média aritmética ponderada}

Às vezes, associam-se os números $X_{1}, X_{2}, X_{3} \ldots X_{k}$ a certos fatores de ponderação ou pesos $W_{1}+W_{2}+\ldots .+W_{k}$, que dependem do significado ou importância atribuída aos números. Nesse caso

$$
\bar{X}=\frac{X_{1} W_{1}+X_{2} W_{2}+X_{3} W_{3}+\ldots+X_{k} W_{k}}{W_{1}+W_{2}+\ldots+W_{k}}=\frac{\sum_{i=1}^{K} X_{i} W_{i}}{\sum_{i=1}^{K} W_{K}}
$$

tem a denominação de média aritmética ponderada, para $i=1, \ldots, k$.

\subsubsection{Média Geométrica}

Por definição, a média geométrica de $\mathrm{n}$ valores não-negativos $\left(X_{1}, X_{2}, \ldots, X_{n}\right)$ é

$$
G=\sqrt[n]{X_{1} X_{2} \ldots X_{n}}=\sqrt[n]{\prod_{i=1}^{n} X_{i}}
$$

$\operatorname{com} i=1,2,3, \ldots N$.

Na prática, G é calculado aplicando-se logaritmos

$$
\log \mathrm{G}=\frac{1}{n} \sum_{i=1}^{n} \log X_{i}
$$

isto é, o logaritmo da média geométrica é igual a média aritmética dos logaritmos dos valores observados.

\subsubsection{Mediana}

Por definição, mediana de um conjunto de dados ordenados (forma crescente ou decrescente) é o valor tal que metade dos dados são iguais ou inferiores a esse valor e metade dos valores são iguais ou superiores a esse valor. 
Então, se os dados estão dispostos em ordem crescente ou decrescente, chamamos mediana ao valor que é precedido e seguido pelo mesmo número de dados.

Assim, se o número de dados de um conjunto ordenado é par, a mediana é, por convenção, a média aritmética dos dois valores centrais. Se for impar será igual ao valor central.

A escolha pela mediana para descrever a série de dados depende do que se busca: um parâmetro com fortes propriedades matemáticas que utilize todos os dados ou apenas uma idéia rápida da tendência central?

Se há valores aberrantes, extremos ou discrepantes na série de dados; se, deseja-se conhecer o ponto central exato da distribuição, ou ainda, se a distribuição dos dados é assimétrica, a escolha da mediana como a medida de tendência central a representar a série de dados parece ser a opção correta.

\subsubsection{Moda}

A moda de um conjunto de números é o valor que ocorre com maior frequiência, ou seja, é o valor mais comum. O cálculo da moda só tem sentido quando o conjunto de dados é bastante grande. Um conjunto de variáveis pode não ter moda (amodal), pode ter uma única moda (unimodal) duas modas (bimodal) ou mais de duas modas (multimodal).

A escolha da moda para representar ou descrever a série visa somente apresentar uma idéia rápida da tendência central. $O$ interesse ao se fazer essa escolha é somente obter o ponto mais típico ou popular dos dados.

Em sintese, a média representa, portanto, um valor médio para a série, ou seja, os valores da série irão girar em torno desse valor. Mas, se existir uma tendência, esse valor não representará corretamente a série. Isso porque quando se estima uma média, supõe-se que a série seja estacionária. Portanto, caso haja uma tendência é 
preciso primeiro eliminar a tendência para que a série fique estacionária para depois calcular as medidas de tendência central.

Se a distribuição for normal, a média, a moda e a mediana são iguais e, se as distribuições forem do tipo exponencial, elas serão diferentes, porque a distribuição é assimétrica. Além disso, a média está associada à distribuição normal, enquanto que a mediana está associada à distribuição exponencial dupla.

Quando forem encontrados "outliers", ou seja, valores discrepantes nas séries de preços, Silver (2000), sugere como alternativa a trimedia, uma medida de tendência central considerada eficiente por ser um estimador robusto da média da população.

Os valores mais altos $(5 \%)$ e os valores mais baixos $(5 \%)$ são removidos para calcular a média com os $90 \%$ das observações restantes, eliminando a influência dos valores extremos.

O a trimedia possui a seguinte fórmula

$$
X_{t k}=\frac{1}{(n-2 k)} \sum_{i=k+1}^{n-k} X_{i}
$$

Calculada após as $k$ menores e as $k$ maiores observações serem eliminadas da amostra, para $0<k<1 / 2$.

Conclui-se então, que a decisão entre qual das medidas de tendência central é a melhor, depende do objetivo fixado. Cada uma delas pode ser a melhor sob diferentes situações. Provavelmente a média é a medida de tendência central mais usada seguida pela mediana.

A média tem a vantagem de incluir cada valor da série de dados em seu cálculo e de ser mais estável do que a mediana ou a moda mas, por outro lado tem a desvantagem de ser muito sensível a valores extremos. A mediana é a melhor medida 
quando a série de dados contêm valores extremos ou então, outra opção é a utilização da Trimedia, medida pouco utilizada pelos estatísticos . A moda é fácil de ser encontrada, mas não é de muito uso em aplicações práticas, ela é utilizada quando pretende-se apenas uma medida rápida e aproximada da tendência central ou descritiva. 


\section{RESULTADOS E DISCUSSÃO}

\subsection{Assimetria}

A assimetria, grau de desvio ou afastamento de simetria de uma distribuição, ou é positiva, quando a distribuição tem curva assimétrica para a direita, ou é negativa, quando a distribuição tem a curva assimétrica à esquerda. Quando a distribuição é normal, tem-se a média, a mediana e a moda iguais e, assim, o coeficiente de assimetria é nulo, uma vez que esse valor é proporcionado pela diferença entre a média e a moda.

Na Tabela 1, para o conjunto de preços de Araçatuba (1), o coeficiente de assimetria é 0,7944 , o que significa que sua distribuição é assimétrica à direita. Já para a amostra Araçatuba (2), o coeficiente é negativo e igual a -0,1413, ou seja, a distribuição é assimétrica à esquerda. Apesar do coeficiente estar bem próximo de zero, ainda assim, existe uma assimetria, mesmo que pouco acentuada.

Tabela 1. Estatística Descritiva.

\begin{tabular}{lccc}
\hline & $\begin{array}{c}\text { Número de } \\
\text { Observações }\end{array}$ & $\begin{array}{c}\text { Coeficiente de } \\
\text { Assimetria }\end{array}$ & $\begin{array}{c}\text { Coeficiente de } \\
\text { Curtose }\end{array}$ \\
\hline Araçatuba (1) & 2160 & 0,7944 & $-0,2077$ \\
Araçatuba (2) & 1119 & $-0,1413$ & $-0,6448$ \\
\hline S. J. do Rio Preto (1) & 3111 & 1,0786 & 0,6955 \\
S. J. do Rio Preto (2) & 963 & $-0,1953$ & $-0,4966$ \\
\hline Bauru/Marília (1) & 1547 & 0,6341 & $-0,5857$ \\
Bauru/Marilia (2) & 691 & $-0,1548$ & $-0,0731$ \\
\hline Presidente Prudente (1) & 1925 & 1,0292 & 0,5187 \\
Presidente Prudente (2) & 566 & $-0,10379$ & $-0,6427$ \\
\hline
\end{tabular}

Fonte: Elaborada pela autora.

Notas: resultados obtidos no SAS. 
Também, pela Tabela 1, tem-se para os preços observados de São José do Rio Preto (1), um coeficiente de assimetria positivo e igual a 1,0786 e portanto, a distribuição é assimétrica à direita. Para o caso (2), a assimetria é novamente negativa $\mathrm{e}$ igual a $-0,1953$ e, com isso a distribuição é pouco, mais ainda assim, assimétrica à esquerda.

Para Bauru/Marília, Tabela 1, a distribuição dos preços é novamente, assimétrica à direita para o caso (1), com o coeficiente igual a 0,6341 , e assimétrica à esquerda para o caso (2), com um coeficiente igual a $-0,1548$.

E finalmente, para o conjunto de preços de Presidente Prudente (1), novamente mostrados pela Tabela 1, o coeficiente de assimetria é igual a 1,0292 e portanto, a distribuição é assimétrica à direita. Já para o caso (2), o coeficiente é igual a 01038, ou seja, sua distribuição é assimétrica à esquerda.

Esta constatação contrasta com Pino et al. (2000), que afirma que os preços não têm uma distribuição normal, uma vez que são sempre positivos com uma distribuição de freqüência que costuma ser assimétrica à direita. Mas, como pode ser observado na Tabela 1, não se pode concluir se realmente os preços, têm sua distribuição assimétrica sempre à direita; uma vez que metade dos conjunto de preços têm assimetria à direita e a outra metade, assimetria à esquerda. Mas, pode-se notar que os preços não têm uma distribuição normal; suas curvas são sempre assimétricas, tanto para a direita quanto para a esquerda; umas com a assimetria mais acentuada como em Presidente Prudente (1) ou pouco acentuadas como no em Presidente Prudente (2).

\subsection{Curtose}

A curtose é o grau de achatamento das distribuições, em relação à distribuição normal. A distribuição normal é conhecida como uma distribuição mesocúrtica; uma vez que sua curva de distribuição não é pontiaguda, ou seja, não é leptocúrtica; nem tem o topo achatado, ou seja, não é platicúrtica. 
$\mathrm{Na}$ tabela 1, os coeficientes de curtose, identificam o formato das distribuições através dos sinais positivo $(+)$ ou negativo $(-)$, ou seja, quando o coeficiente de curtose for positivo, a curva de distribuição é conhecida como leptocúrtica e, quando o sinal for negativo, elas são conhecidas como platicúrticas.

Para o conjunto de preços de Araçatuba, apresentado na Tabela 1, tanto para o caso (1) quanto para o caso (2), tem-se o coeficiente de curtose negativo igual a 0,2077 e $-0,6448$, respectivamente. E portanto, ambas as distribuições são platicúrticas, ou seja, têm seu topo mais achatado. Já para São José do Rio Preto, para o caso (1), a Tabela 1, o conjunto de preços tem o coeficiente posititvo, igual a 0,6955 e portanto a distribuição é mais pontiaguda, ou seja, leptocúrtica. Para o caso (2), o coeficiente é igual a -0,4966 e portanto, a distribuição é platicúrtica.

Para Bauru/Marília, Tabela 1, o coeficiente de curtose é negativo tanto para o caso (1), quanto para o caso (2). E portanto, as distribuições são novamente platicúrticas. Para o conjunto de preços de Presidente Prudente, tem-se para o caso (1), o coeficiente igual a 0,5187 e para o caso (2), igual a $-0,6427$. E portanto, para o caso(1), a distribuição é leptocúrtica e para o caso (2), a distribuição é platicúrtica.

Estes resultados, não estão de acordo com os de Mandelbrot $(1963,1967)$, que mostrou, que a distribuição da variação de preços especulativo é mais pontiaguda que a normal, ou seja, é leptocúrtica. Mas, analisando os resultados apresentados pela Tabela 1, verifica-se que todos, exceto o de São José do Rio Preto (1) e o de Presidente Prudente (1), têm sua curva de distribuição com o topo achatado, ou seja, as distribuições são platicúrticas uma vez que os coeficientes de curtose são negativos. Isso significa, uma acentuada dispersão dos valores da variável preço, neste caso.

Portanto, pelos resultados apresentados na Tabela 1, pode-se afirmar que os preços costumam ter uma distribuição platicúrtica, isto é, uma curva mais achatada. Caso as distribuições sejam leptocúrticas, têm-se uma grande concentração dos valores da variável preço, em torno da média, uma vez que as curvas das distribuições serão mais pontiagudas. 


\subsection{Medidas de Posição}

As medidas que descrevem a posição ou a tendência central, como já mencionado, são a média, a mediana e a moda. Quando essas medidas não coincidem, as distribuições dos preços não seguem uma distribuição normal.

Para os preços de Araçatuba (1), como observado na Tabela 2, percebe-se que a mediana e a moda estão bem próximas mas, já a média, difere em relação às duas medidas. Para o caso (2), é a moda que difere em relação às outras duas, ou seja, a média e a mediana estão bem próximas. Portanto, esses preços não têm uma distribuição normal uma vez que as três medidas de posição não coincidem.

Tabela 2. Medidas de Posição.

\begin{tabular}{lccc}
\hline & Média & Mediana & Moda \\
\hline Araçatuba (1) & 28,3582 & 27,6326 & 27,5002 \\
Araçatuba (2) & 38,1944 & 38,3343 & 39,3099 \\
\hline S. J. do Rio Preto(1) & 28,0337 & 27,4914 & 25,7361 \\
S. J. do Rio Preto (2) & 38,2858 & 38,4309 & 40,1919 \\
\hline Bauru/Marilia (1) & 28,3923 & 27,6879 & 27,5002 \\
Bauru/Marília (2) & 38,3938 & 38,5297 & 40,2908 \\
\hline Presidente Prudente (1) & 27,8491 & 27,1446 & 25,4784 \\
Presidente Prudente (2) & 37,9180 & 37,9860 & 36,8759 \\
\hline
\end{tabular}

Fonte: Elaborada pela autora.

Notas: resultados obtidos no SAS.

Para o conjunto de preços de São José do Rio Preto, tem-se uma situação um pouco diferente; para o caso (1), como pode ser observado pela Tabela 2, as três medidas de posição diferem-se umas das outras; e portanto, esses preços estão bem longe de terem sua distribuição normal. Já no caso (2), a média e a mediana estão bem próximas, tornando possível observar uma tendência à normalidade.

Pela Tabela 2, para Bauru/Marília, tem-se para os conjuntos de preços, caso (1) e caso (2), as medidas de posição diferentes entre si. No caso (2), os valores da média e da mediana são bem próximos mas, não chegam a ser iguais. $\mathrm{O}$ mesmo ocorre para Presidente Prudente, como pode ser observado novamente pela Tabela 2, para os 
dois casos as medidas nos conjuntos de preços, diferem entre si. No caso (2), os valores da média e da mediana, novamente, são bem próximos.

Pelos resultados, mais uma vez, pode-se concluir, que as distribuições dos preços não são normais. No caso em que os valores da média e da mediana se aproximam, a distribuição pode até aproximar-se mais da normalidade.

\subsection{Medidas de Dispersão}

Três das medidas que descrevem a dispersão ou variabilidade dos dados são a variância, o desvio padrão e a amplitude. A amplitude não é uma boa medida de dispersão uma vez que só leva em consideração os valores extremos. Já o desvio padrão e a variância, medem, ambos, o afastamento médio dos dados em relação à média do conjunto mas, o desvio padrão é expresso na mesma unidade dos valores do conjunto de dados, facilitando a interpretação dos resultados.

Pelo resultados, apresentados pela Tabela 3, tem-se um desvio padrão relativamente baixo; Araçatuba (1) tem seu desvio padrão igual a 2,3591, o maior valor e, Bauru/Marília (2), tem o menor desvio igual a 1,7160. Dependendo do valor do desvio padrão, a distribuição terá a sua base mais ou menos estreita e seu pico mais pontiagudo ou mais achatado, ou seja, quanto maior o valor do desvio, mais se alonga sua base e diminui a altura de seu pico.

Tabela 3. Medidas de Variabilidade.

\begin{tabular}{lccc}
\hline & Amplitude & Desvio Padrão & Variância \\
\hline Araçatuba (1) & 14,2319 & 2,3591 & 5,5655 \\
Araçatuba (2) & 9,6169 & 1,9047 & 3,6279 \\
\hline S. J. do Rio Preto (1) & 18,3066 & 2,0987 & 4,4047 \\
S. J. do Rio Preto (2) & 9,1811 & 1,7927 & 3,2139 \\
\hline Bauru/Marília (1) & 11,2291 & 2,2115 & 4,8906 \\
Bauru/Marília (2) & 8,1749 & 1,7160 & 2,9448 \\
\hline Presidente Prudente (1) & 13,5459 & 2,2130 & 4,8975 \\
Presidente Prudente (2) & 9,3172 & 1,7739 & 3,1470 \\
\hline
\end{tabular}

Fonte: Elaborada pela autora.

Notas: resultados obtidos no SAS. 
Portanto, pelo valor do desvio padrão, Araçatuba (1) tem sua distribuição com uma base mais alongada e seu pico mais achatado. Mas, como os valores não se distanciam muito uns dos outros, as distribuições de todos os exemplos não diferem muito uma das outras em relação à dispersão dos dados.

\subsection{Testes Estatísticos para a Normalidade}

Foram utilizados três testes estatísticos. Quando o tamanho da amostra for menor ou igual a 2000, utiliza-se o teste W de Shapiro-Wilk além do teste D de Kolmogorov-Smirnov e o teste de Lilliefors, baseados na função de distribuição empírica.

Com esses testes, é possível determinar quando rejeitar a hipótese nula examinando a probabilidade associada ao teste estatístico. Quando o p-value é menor do que o valor crítico predeterminado, no caso, adotou-se 0,05 , como usualmente é feito, rejeita-se a hipótese nula, neste caso, a hipótese de normalidade.

\subsubsection{Teste W}

Os conjuntos de preços de Araçatuba (1) e de São José do Rio Preto (1), não apresentam o teste $\mathrm{W}$, como pode ser observado na Tabela 4 uma vez que o número de suas observações, ultrapassou o valor 2000; 2160 dados e 3111 dados, Tabela 1, respectivamente. 
Tabela 4. Testes Estatísticos para a Normalidade.

\begin{tabular}{lcc}
\hline & W & D \\
\hline Araçatuba (1) & - & $0,0138^{*}$ \\
Araçatuba (2) & $0,9863^{*}$ & $0,0964^{*}$ \\
\hline S. J. do Rio Preto (1) & - & $0,1565^{*}$ \\
S. J. do Rio Preto (2) & $0,9856^{*}$ & $0,0880^{*}$ \\
\hline Bauru/Marília (1) & $0,9304^{*}$ & $0,1408^{*}$ \\
Bauru/Marília (2) & $0,9811^{*}$ & $0,1043^{*}$ \\
\hline Presidente Prudente (1) & $0,9042^{*}$ & $0,1535^{*}$ \\
Presidente Prudente (2) & $0,9860^{*}$ & $0,0842^{*}$ \\
\hline
\end{tabular}

Fonte: Elaborada pela autora.

Notas: a estatística W é apresentada por Shapiro-Wilk (1965); a estatística D, por Siegel (1975); * valor significativo a $5 \%$.

Observa-se pela Tabela 4, que para o conjunto de preços de Bauru/Marília, com uma amostra de tamanho 1547 para o caso (1) e 691 para o caso (2), o teste W é significativo, ou seja, ao nível de significância 0,05 , rejeita-se a hipótese de normalidade para ambos os casos. Também para Presidente Prudente, Tabela 4, para ambos os casos (1) e (2), com 1925 e 566 preços, Tabela 1, respectivamente, o teste $\mathrm{W}$ foi significativo, ou seja, rejeitou a hipótese de normalidade para os conjuntos de preços.

Segundo Shapiro (1990), esse teste pode não ser tão eficiente com amostras muito grandes $(n \geq 50)$ mas, nos resultados apresentados na Tabela 4 , o teste se mostrou bastante eficiente e especialmente sensivel à assimetria, ou seja, mesmo as amostras apresentando uma assimetria pouco acentuada, o teste foi significativo para todas elas.

\subsubsection{Teste de Kolmogorov - Smirnov ( Teste D)}

É um teste que pertence à classe das estatísticas das funções de distribuição empírica. Essa classe de estatísticas é baseada na maior diferença vertical entre $F(x)$ e Fn(x), ou seja, na discrepância entre a distribuição empírica e a distribuição hipotética estimada. 
Também para esse teste, rejeita-se a hipótese de normalidade, quando o $p$-value for menor do que o valor crítico predeterminado 0,05 . Esse teste, ao contrário do teste W, não depende do tamanho da amostra para ser aplicado. É um teste de aderência aplicado às amostras para se testar a normalidade.

Pode-se notar portanto, que independente do tamanho da amostra, o teste de Kolmogorov-Smirnov é eficiente, ou seja, mesmo para amostras com diferentes número de dados, como nos casos de São José do Rio Preto (1) com 3111 dados ou de Presidente Prudente (2) com 566 dados, Tabela 1, o teste foi significativo.

Para o conjunto de preços de Araçatuba (1), que apresenta um grande número de dados em sua amostra, observa-se pela Tabela 4, que o teste $D$ foi significativo ao nível se significância 0,05 . Para o caso (2), com uma amostra de tamanho1119, mais uma vez o teste foi signicativo, ou seja, rejeita-se novamente a hipótese de normalidade. Também para o caso de Presidente Prudente (2), que apresenta a menor amostra, 566 dados, Tabela 1,0 teste $\mathrm{D}$, rejeita a hipótese de normalidade ao nível se significância 0,05 como observado na Tabela 4 . E para o caso (1), com uma amostra de tamanho igual a 1925, o teste foi significativo também.

Para os demais resultados, como observado na Tabela 4, tem-se o teste $\mathrm{D}$ de Kolmogorov-Smirnov significativo. Ou seja, rejeita-se a hipótese de normalidade em todos os conjuntos de preços. Percebe-se, portanto, que este teste não tem restrições quanto ao tamanho da amostra e que é eficaz ao rejeitar a hipótese nula quando esta está incorreta.

\subsubsection{Teste de Lilliefors}

É uma modificação ao teste de Kolmogorov-Smirnov introduzida por Lilliefors, ampliando seu uso aos casos em que a média e variância não são especificadas, são estimadas através dos dados da amostra. Esse teste, foi feito através do softwer Estatística. E, mais uma vez, para todos os exemplos, o teste foi significativo a um nível de significância igual a 0,05 . 
Para os preços do conjunto Araçatuba (1), como apresentado na Figura 1, o teste de Lilliefors, foi significativo, ou seja, a hipótese de normalidade foi rejeitada e olhando para o gráfico apresentado, percebe-se que a distribuição dos dados não pode realmente ser considerada normal.

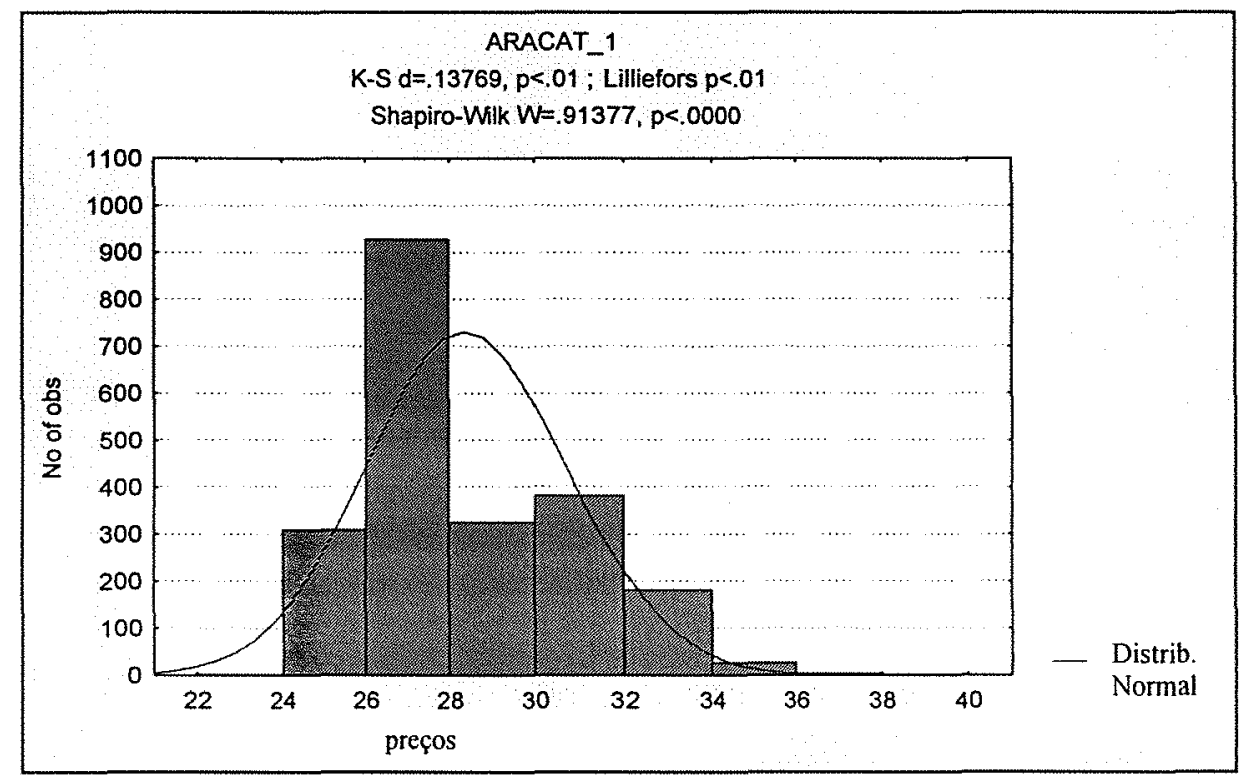

Figura 1. Teste de Lilliefors para Araçatuba (1).

Fonte: CEPEA, 1998; Estatística.

Esse teste também não apresenta restrições quanto ao tamanho da amostra. Pode-se notar que em todos os resultados, ele foi significativo. Tanto para Araçatuba (1), Figura 1 com 2160 dados quanto para Presidente Prudente (2), Figura 2, com 566 dados. 


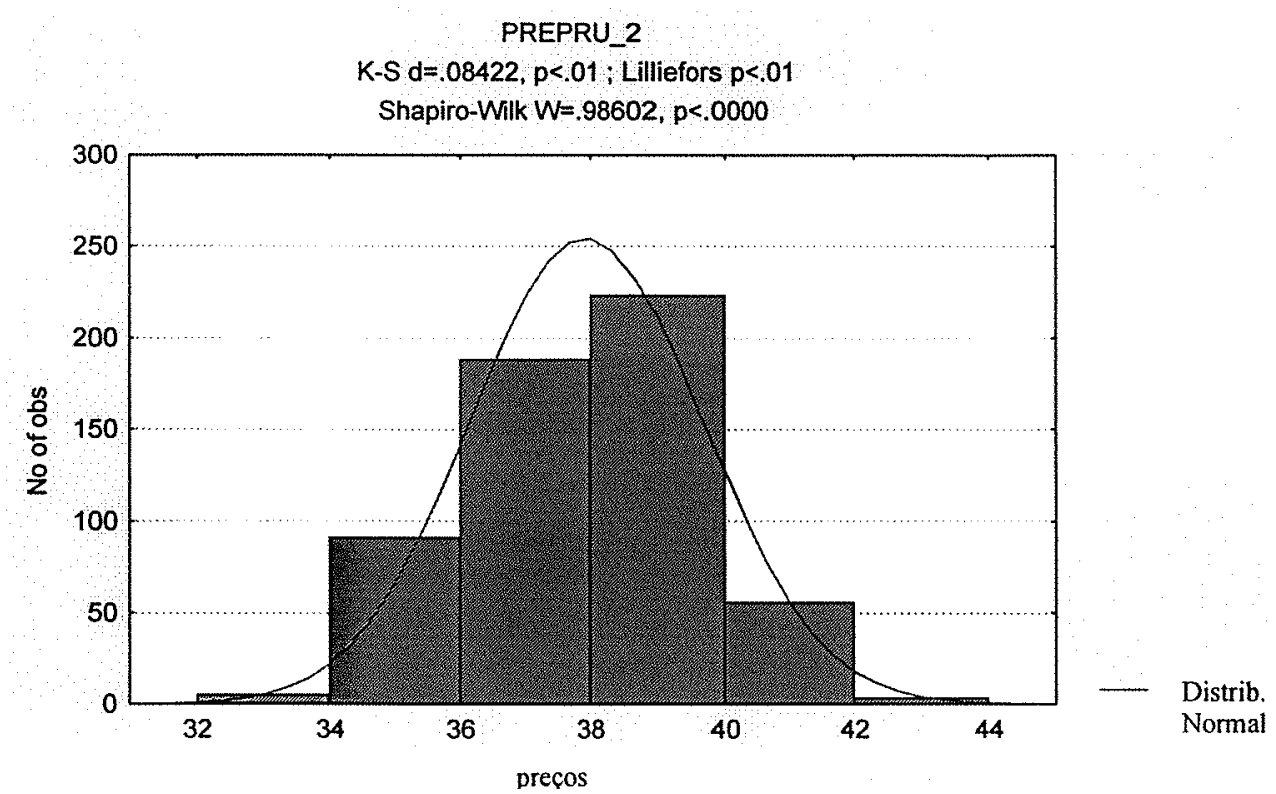

Figura 2. Teste de Lilliefors para Presidente Prudente (2).

Fonte: CEPEA, 1999; Estatística.

Para o conjunto de preços de Bauru/Marília (2), como pode ser observado na Figura 3, o teste de Lilliefors foi significativo e, portanto, ao nível de significância $5 \%$, rejeita-se novamente a hipótese de normalidade da amostra. 


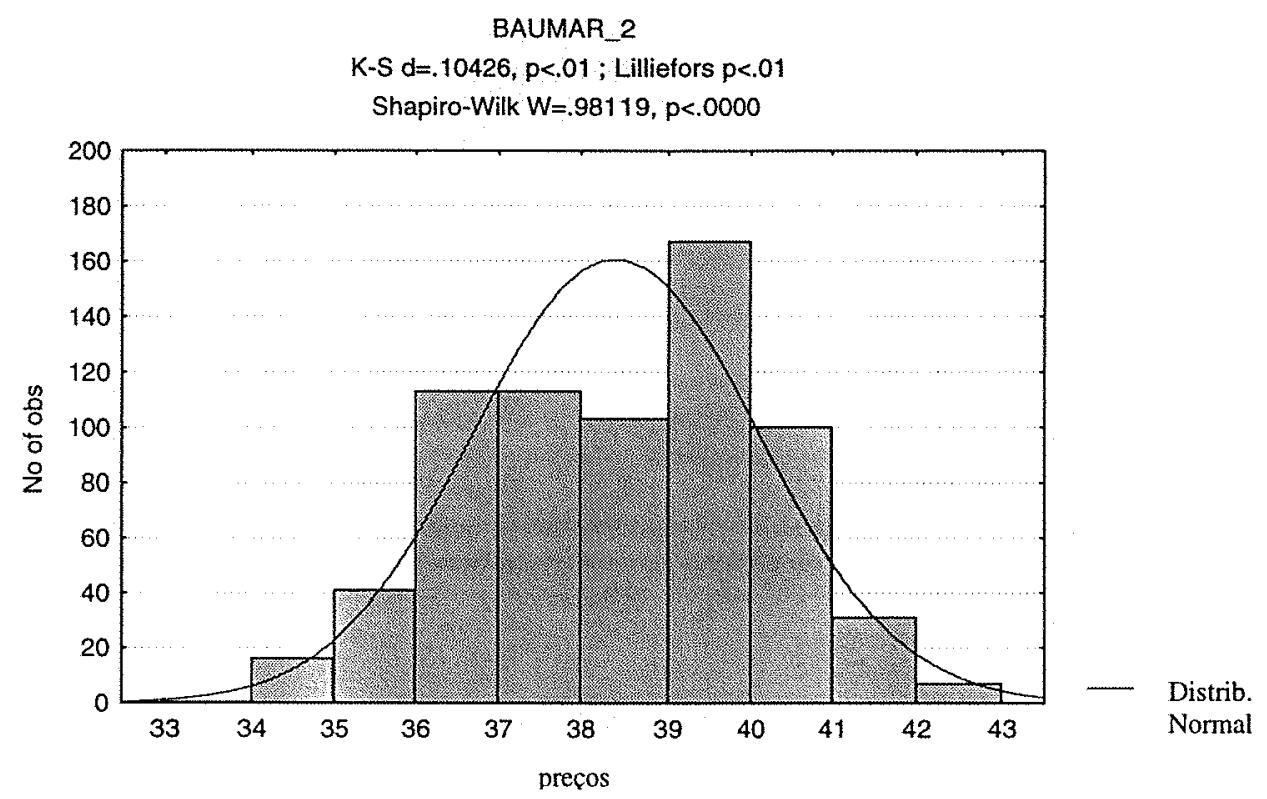

Figura 3. Teste Lilliefors para Bauru/Marília (2).

Fonte: CEPEA, 1999; Estatística.

Os resultados para o conjunto de dados das demais regiões encontram-se no anexo A1. Pode-se perceber que para todos eles, o teste de Lilliefors foi significativo, ou seja, para todos os conjuntos de dados, rejeita-se a hipótese de normalidade.

\subsection{Gráfico de Caixas}

Artifício gráfico que facilita a visualização da distribuição das variáveis em estudo, uma vez que resume um conjunto de dados exibindo diversas características.

Para o conjunto de preços de Araçatuba (1), como pode ser observado na Figura 4, os preços do Boi Gordo realmente não apresentam uma distribuição normal; os valores representados por " 0 ", são os preços que se encontram na região crítica, são os valores que devem ser vistos com cautela, não chegam a ser considerados outliers mas também, não se encaixam na distribuição normal. 


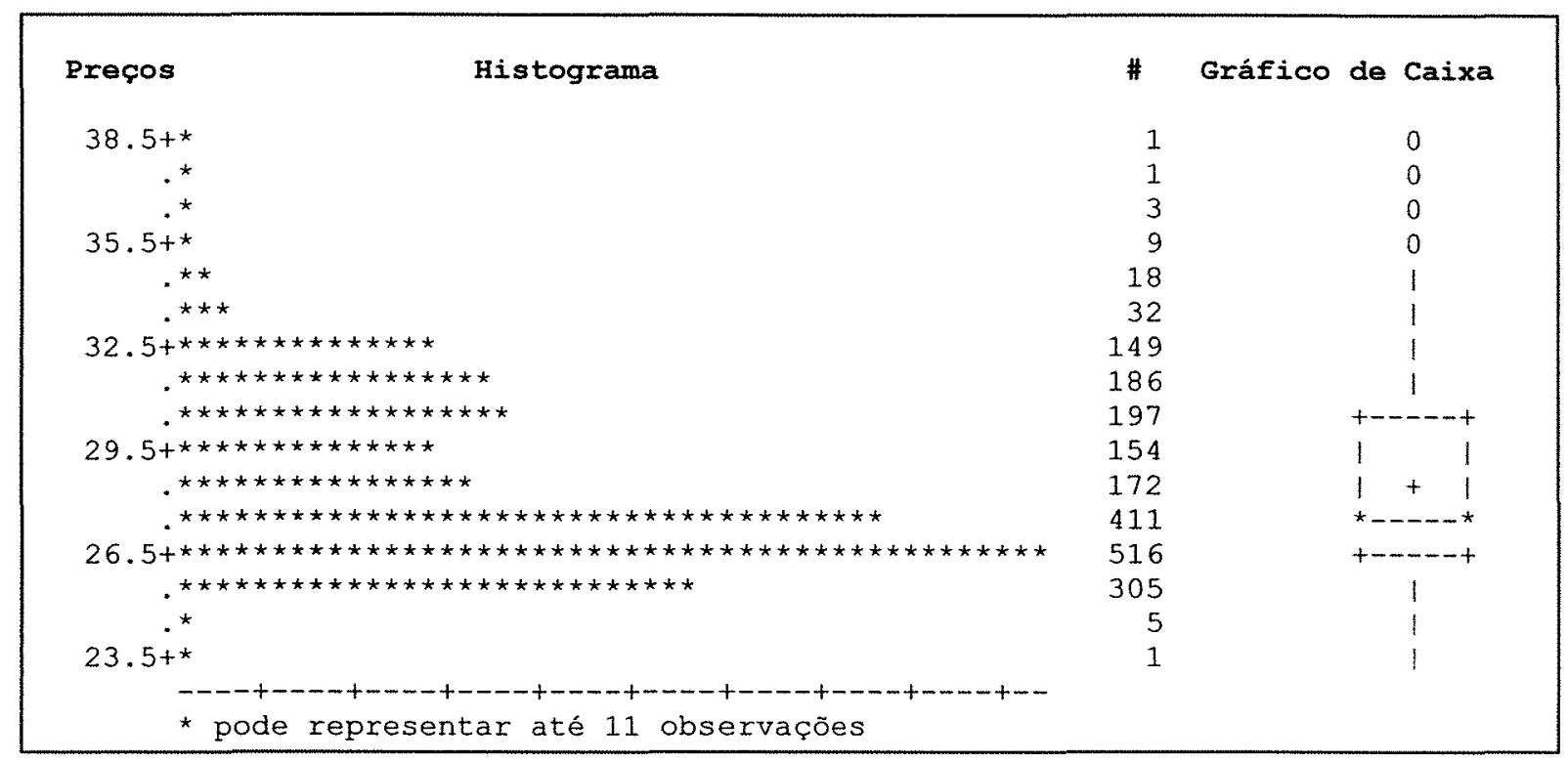

Figura 4. Gráfico de Caixa para Araçatuba (1).

Fonte: CEPEA, 1998; SAS.

Já para o resultado de Araçatuba (2), se a análise fosse feita somente através do gráfico de caixa apresentado pela Figura 5, poderia se chegar a uma conclusão errada pois pelo gráfico, a distribuição poderia ser considerada normal, uma vez que a média e a mediana estão muito próximas, mas com as análises apresentadas acima, simetria, curtose, medidas de dispersão, além dos testes estatísticos, não se pode afirmar que a distribuição seja normal. 


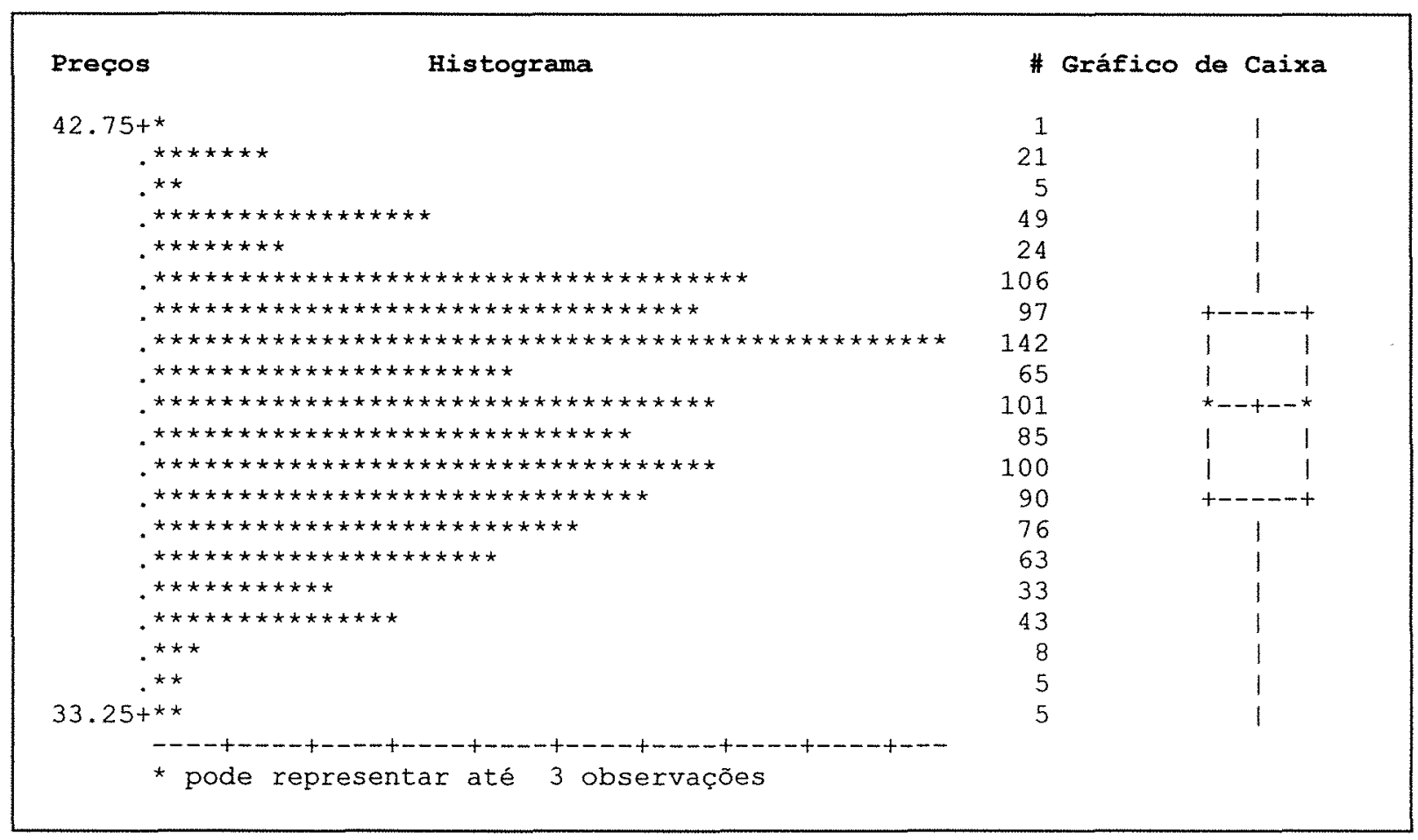

Figura 5. Gráfico de Caixa para Araçatuba (2).

Fonte: CEPEA, 1999; SAS.

O conjunto de preços de São José do Rio Preto (2), tem a média coincidindo com a mediana e, pelo gráfico de caixa, apresentado na Figura 6, também poderia ser considerada a normalidade dos dados. Mais uma vez, por todos os outros resultados apresentados acima, a distribuição não pode ser considerada normal. 


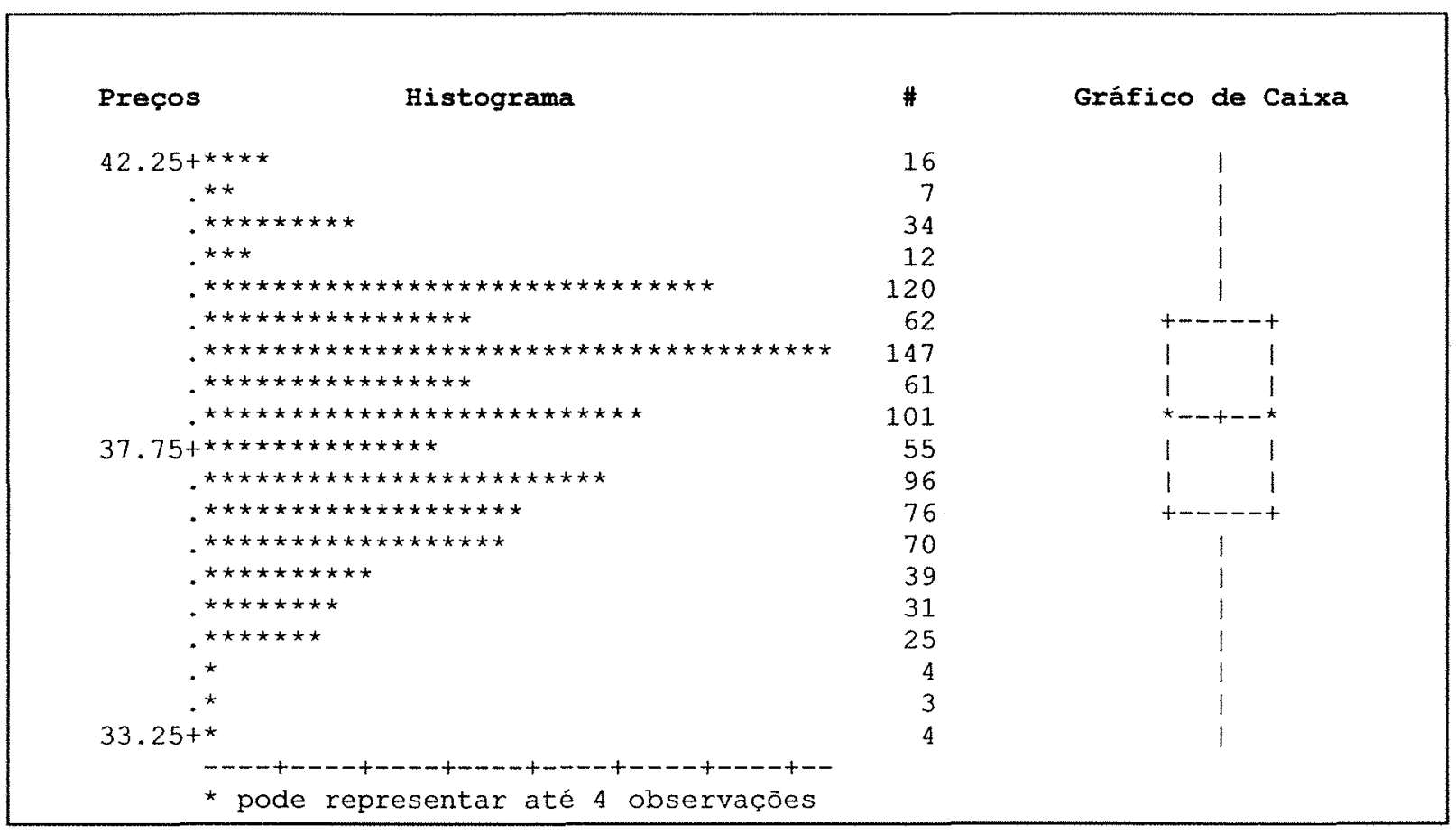

Figura 6. Gráfico de Caixa para São José do Rio Preto (2). Fonte: CEPEA, 1999; SAS.

Para o conjunto de preços de Bauru/Marília, pode-se notar, para o caso (2), Figura 7, que a distribuição é assimétrica à esquerda. Com uma assimetria bem acentuada como pode ser observado graficamente. Já para o de Presidente Prudente (1) tem-se assimetria à direita dos dados. Além de valores pertencentes à região crítica, valores estes, que não se ajustam adequadamente à distribuição normal. 


\begin{tabular}{|c|c|c|}
\hline Histograma & \# & Gráfico de Caixa \\
\hline 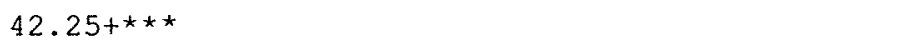 & 7 & 1 \\
\hline.$* \star \star$ & 8 & 1 \\
\hline 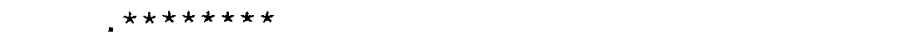 & 23 & i \\
\hline 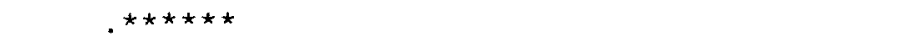 & 16 & 1 \\
\hline 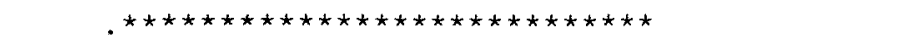 & 84 & i \\
\hline 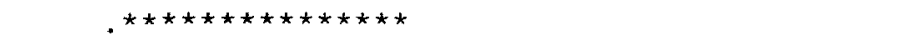 & 43 & $+-\cdots--+$ \\
\hline 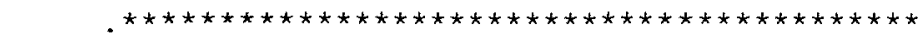 & 124 & 1 \\
\hline 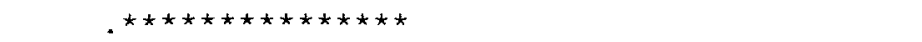 & 43 & * $-\ldots-\ldots *$ \\
\hline 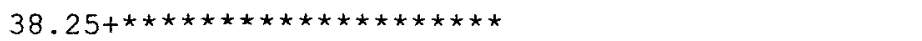 & 60 & $1+1$ \\
\hline 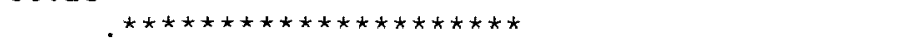 & 61 & $1 \quad 1$ \\
\hline 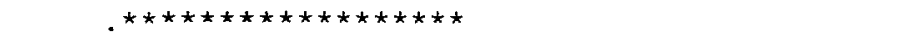 & 52 & +----+ \\
\hline 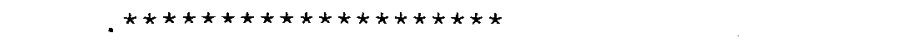 & 60 & 1 \\
\hline 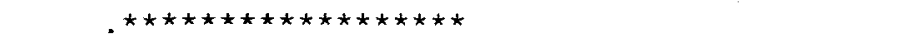 & 53 & $i$ \\
\hline 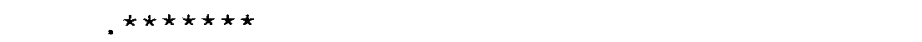 & 21 & $i$ \\
\hline 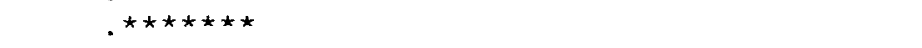 & 20 & $i$ \\
\hline 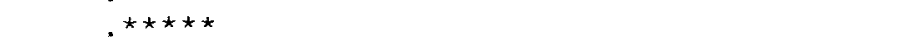 & 15 & $i$ \\
\hline $34.25+*$ & 1 & $i$ \\
\hline * pode representar até 3 observacões & & \\
\hline
\end{tabular}

Figura 7. Gráfico de Caixa para Bauru/Marília (2).

Fonte: CEPEA, 1999; SAS.

\begin{tabular}{|c|c|c|}
\hline Histograma & \# & Gráfico de Caixa \\
\hline 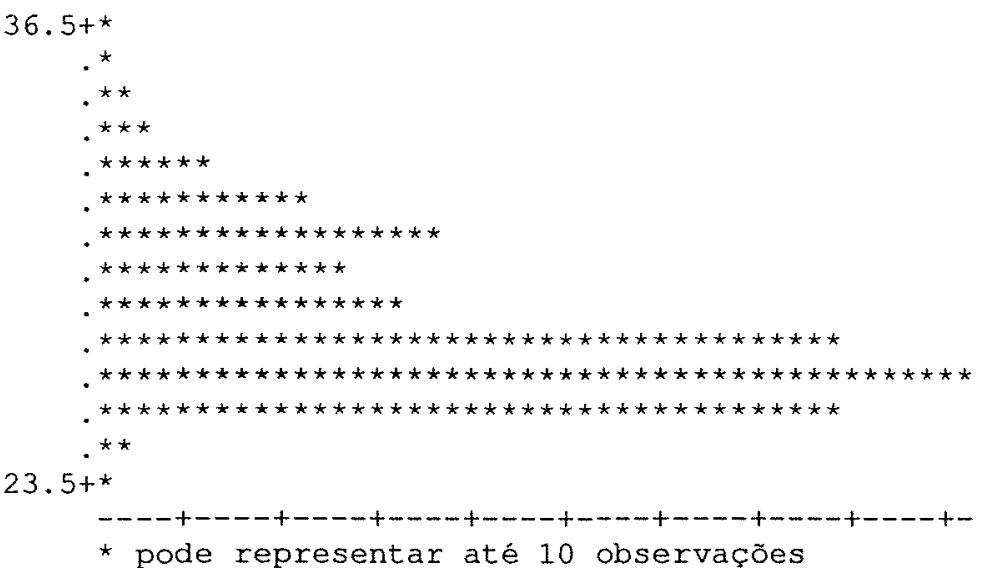 & $\begin{array}{r}3 \\
8 \\
12 \\
23 \\
53 \\
108 \\
180 \\
125 \\
156 \\
388 \\
459 \\
389 \\
20 \\
1\end{array}$ & 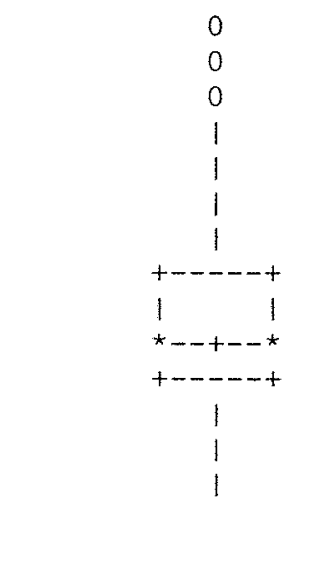 \\
\hline
\end{tabular}

Figura 8. Gráfico de Caixa para Presidente Prudente (1).

Fonte: CEPEA, 1998; SAS. 
O gráfico de Caixa, (Quadro 1) facilita a visualização da distribuição, apresentando vários detalhes; o primeiro e terceiro quartis, a mediana, os limites e as regiões de alerta mas, para uma análise dos resultados não é suficiente. Nos exemplos, Araçatuba (2) e São José do Rio Preto (2), só pela análise gráfica, poderia se chegar a conclusão de normalidade uma vez que a média e a mediana estão coincidindo.

Mas, analisando os valores exatos da média e da mediana, percebe-se que eles são bem próximos mas, não coincidem. E, analisando cada um dos pontos discutidos, assimetria, curtose e os testes para a normalidade, chega-se a conclusão de que essas amostras de preços, não têm uma distribuição normal.

Os demais resultados estão apresentados no anexo A2.

\subsection{Normal Plot}

Considerado um artifício gráfico, visa também, facilitar a visualização das distribuições e análise dos resultados. O sinal de mais (+) que aparece no gráfico, representa a situação ideal, ou seja, representa a normalidade. Já os asteriscos $\left(^{*}\right)$ representam os valores observados das amostras. Uma distribuição normal terá os sinais de mais e os asteriscos, sobrepostos um ao outro.

No resultado de Araçatuba, percebe-se que para o caso (1) que os dados estão bem longe da normalidade, como pode ser observado na Figura 9, uma vez que os dados não se sobrepõem à situação ideal. Para o caso (2), Figura 10, o que se percebe, é uma tendência à normalidade, os dados observados e a situação ideal se sobrepõem. 


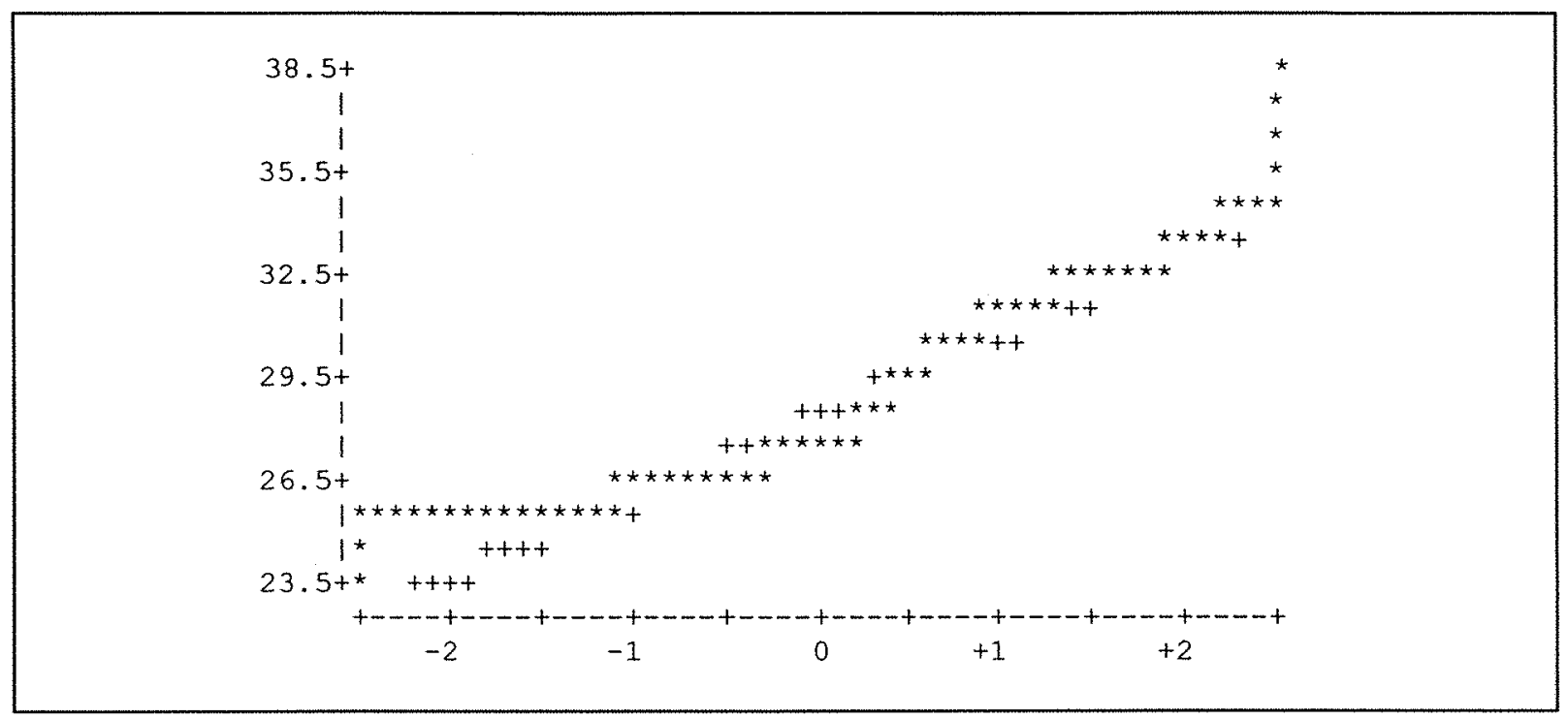

Figura 9. Normal Plot para Araçatuba (1).

Fonte: CEPEA, 1998; SAS.

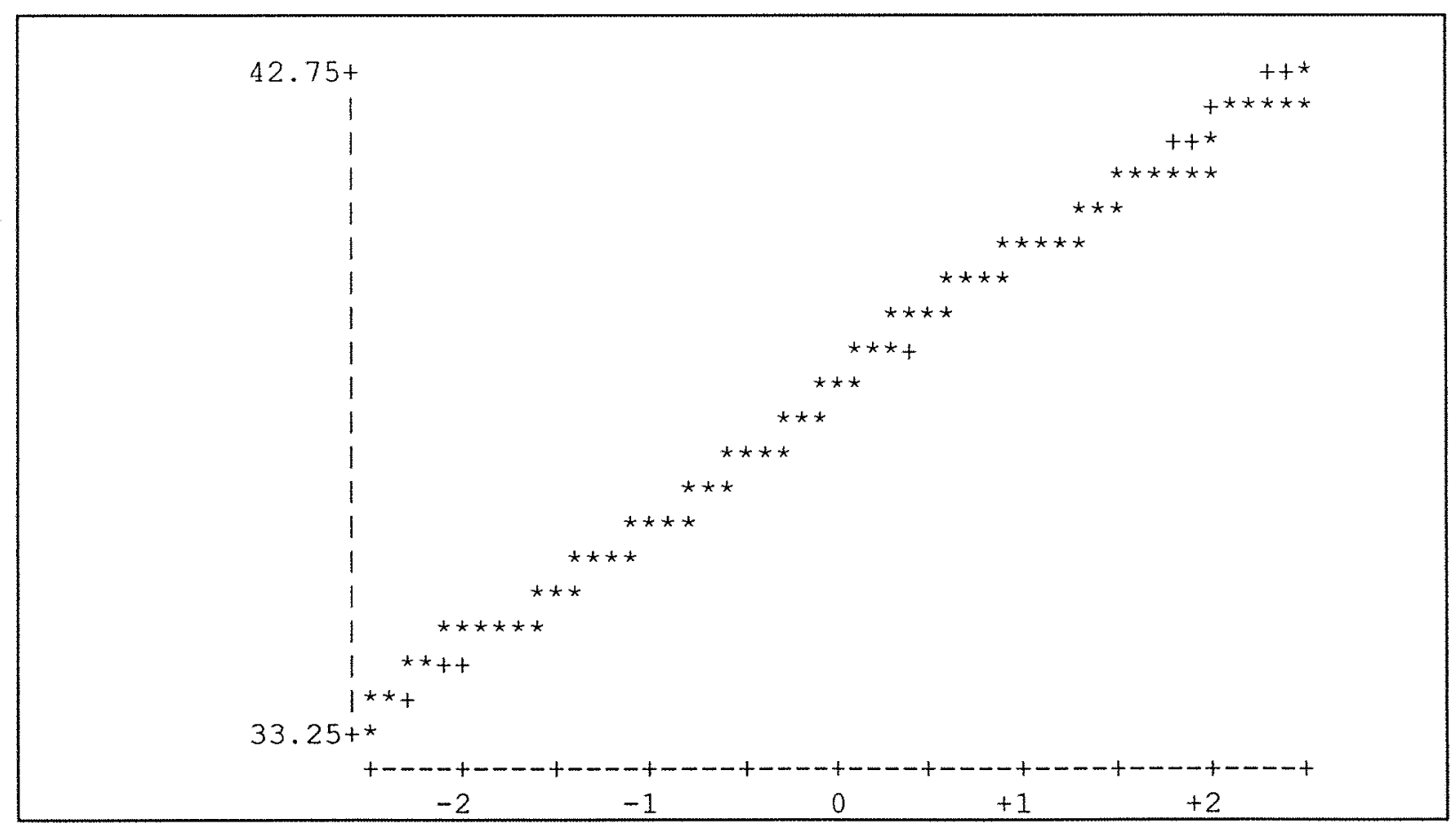

Figura 10. Normal Plot para Araçatuba (2).

Fonte: CEPEA, 1999; SAS. 
Para o conjunto de preços de São José do Rio Preto (2), Figura 11, tem-se os dados bem próximos da situação ideal, ou seja, os dados observados e a situação ideal estão se sobrepondo. Já para o de Bauru/Marília (1), os dados se apresentam distantes da situação ideal; pelo gráfico apresentado na Figura 12, pode-se visualizar o quanto esses dados se afastam da normalidade.

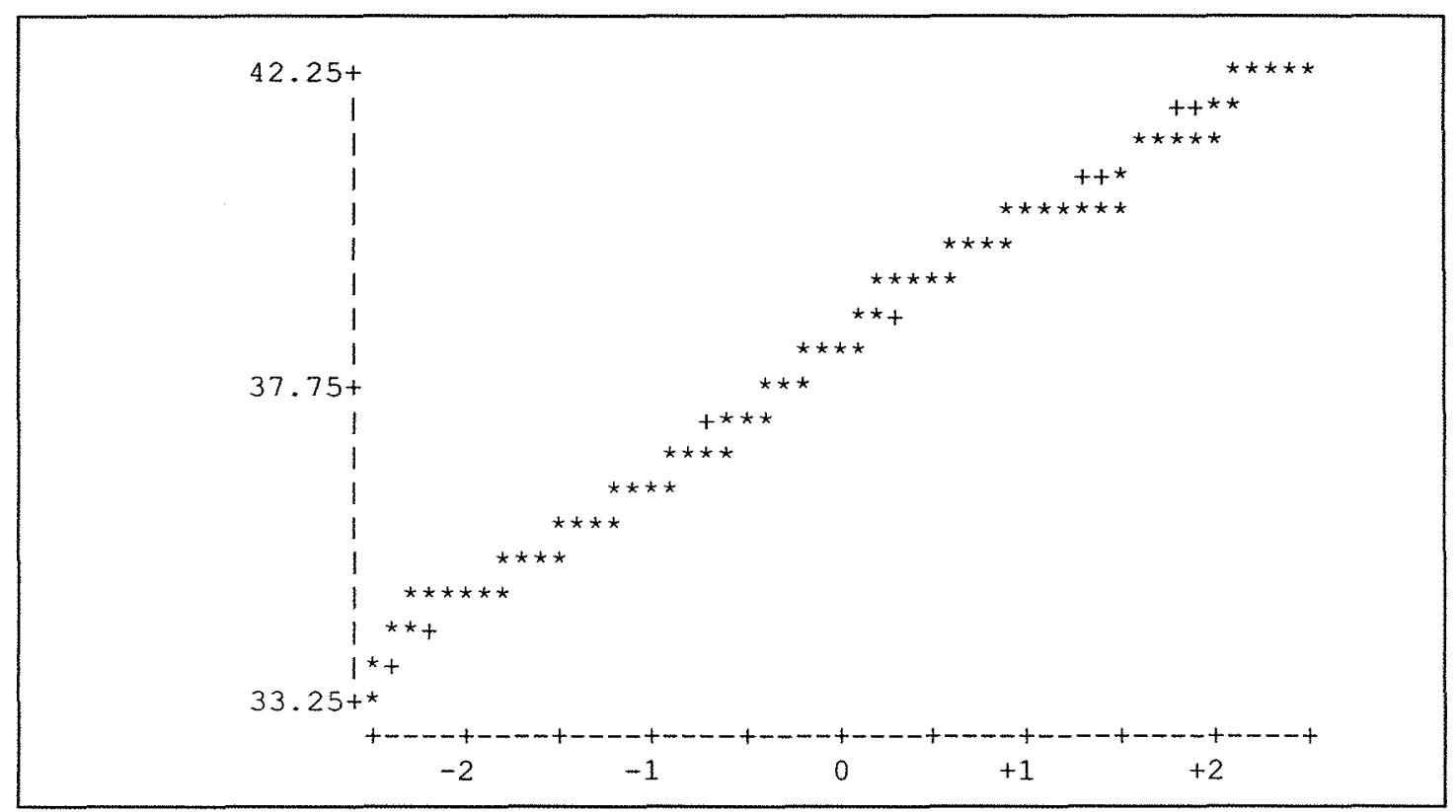

Figura 11. Normal Plot para São José do Rio Preto (2). Fonte: CEPEA, 1999; SAS. 


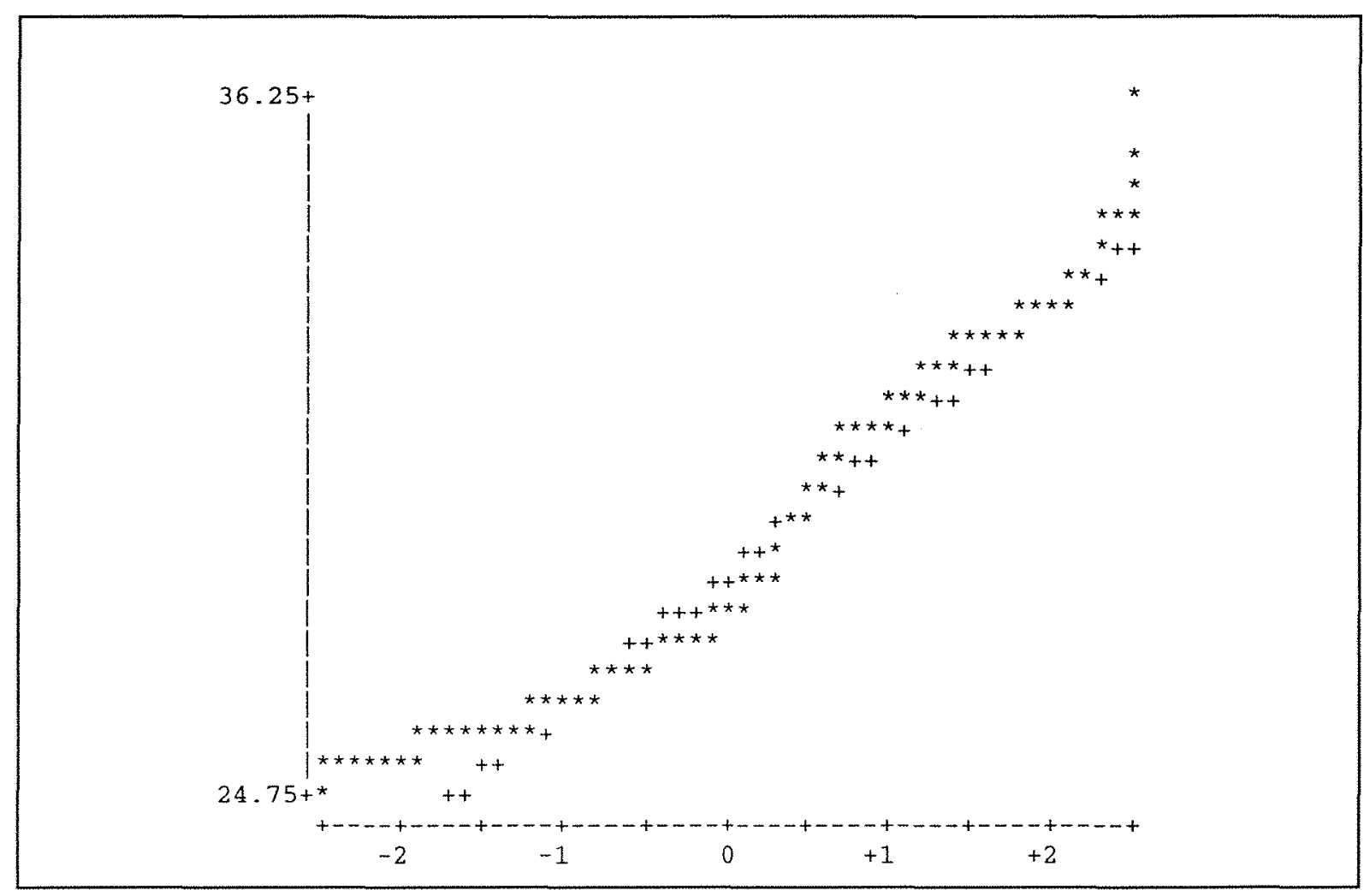

Figura 12. Normal Plot para Bauru/Marília (1). Fonte: CEPEA, 1998; SAS.

Percebe-se que um artifício gráfico, como o Normal Plot e até mesmo como o gráfico de caixa, pode ser muito útil para uma visualização da distribuição mas as vezes, não é o suficiente para determinar se realmente a distribuição é normal ou não. Para essa conclusão, deve-se analisar também outras características como por exemplo, as medidas de posição e as de dispersão, além dos testes estatísticos.

Para os demais resultados, apresentados no anexo $\mathrm{A} 3$, pode-se perceber que as distribuições, fogem da normalidade uma vez que os preços não se sobrepõem à situação ideal. 


\section{CONCLUSÃO}

Este trabalho teve por objetivo o estudo da distribuição teórica dos preços do boi gordo em quatro municípios do estado de São Paulo, principalmente no que diz respeito à hipótese de normalidade destas distribuições. Os dados foram testados para cada município isoladamente, em dois períodos de tempo distintos. Os resultados obtidos levam à conclusão de que os preços mencionados não possuem distribuição normal, na maioria dos casos analisados.

Desta forma, a média não seria a medida de tendência central mais adequada para descrever as referidas distribuições, para o que a mediana seria uma medida mais adequada. Isto porque a mesma não é afetada por valores extremos ou discrepantes que possam vir a ser considerados uma vez que as distribuições são assimétricas. Caso os preços venham a ter distribuição normal, as medidas de tendência central, média, mediana e moda, serão iguais. Desta forma, o uso da mediana como estatística seria uma boa opção, tanto para séries com distribuição normal quanto para séries com distribuição assimétrica. A mediana apresenta ainda como característica desejável o fato de ser uma medida robusta, conhecida, e de fácil cálculo.

Este estudo se constituiu em uma primeira abordagem da questão. Sendo os estudos desta natureza bastante escassos na literatura nacional, algumas sugestões para futuras pesquisas podem ainda ser feitas. Inicialmente, deve-se verificar que as análises foram feitas para cada região isoladamente. Seria importante que futuros estudos estendessem a presente análise para os dados em conjunto, de forma a se ter uma visão mais abrangente a nível estadual. 
Da mesma forma, este estudo conclui que as distribuições analisadas são diferentes da normal, mas não identifica a distribuição que melhor descreve os dados, nem analisa as possíveis transformações que a poderiam tornar normal. A realização de estudos que procurem identificar estas distribuições, suas transformações, sua eventual modificação durante o ano, e sua relação com os fundamentos do mercado do boi gordo no Brasil seriam ainda importantes contribuições para os estudos sobre a formação do preço deste importante produto da pecuária. 
ANEXOS 
Testes de Lilliefors para Normalidade

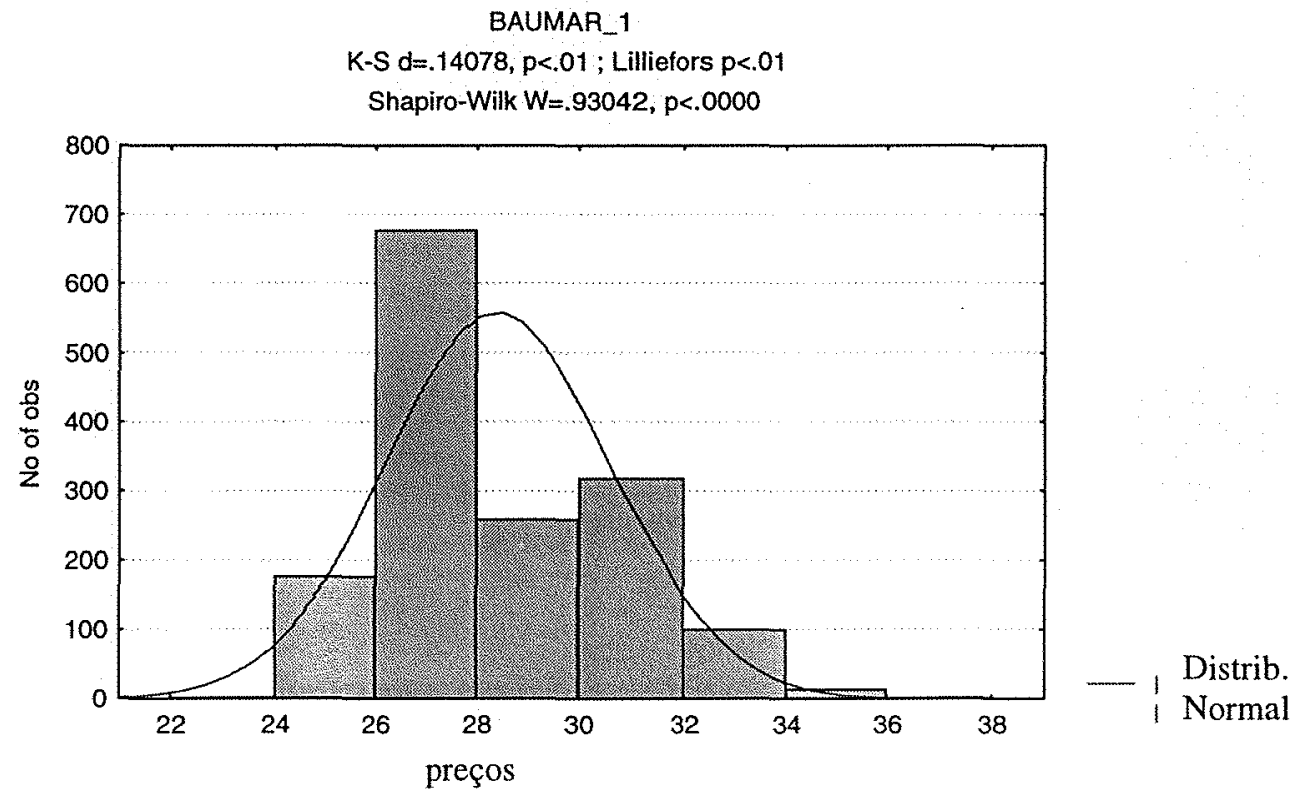

Figura 13. Teste de Lilliefors para Bauru/Marília (1).

Fonte: CEPEA, 1998; Estatística.

PREPRU_1

$K-S d=.15346, p<.01$; Lilliefors $p<.01$

Shapiro-Wilk W=.90419, $p<.0000$

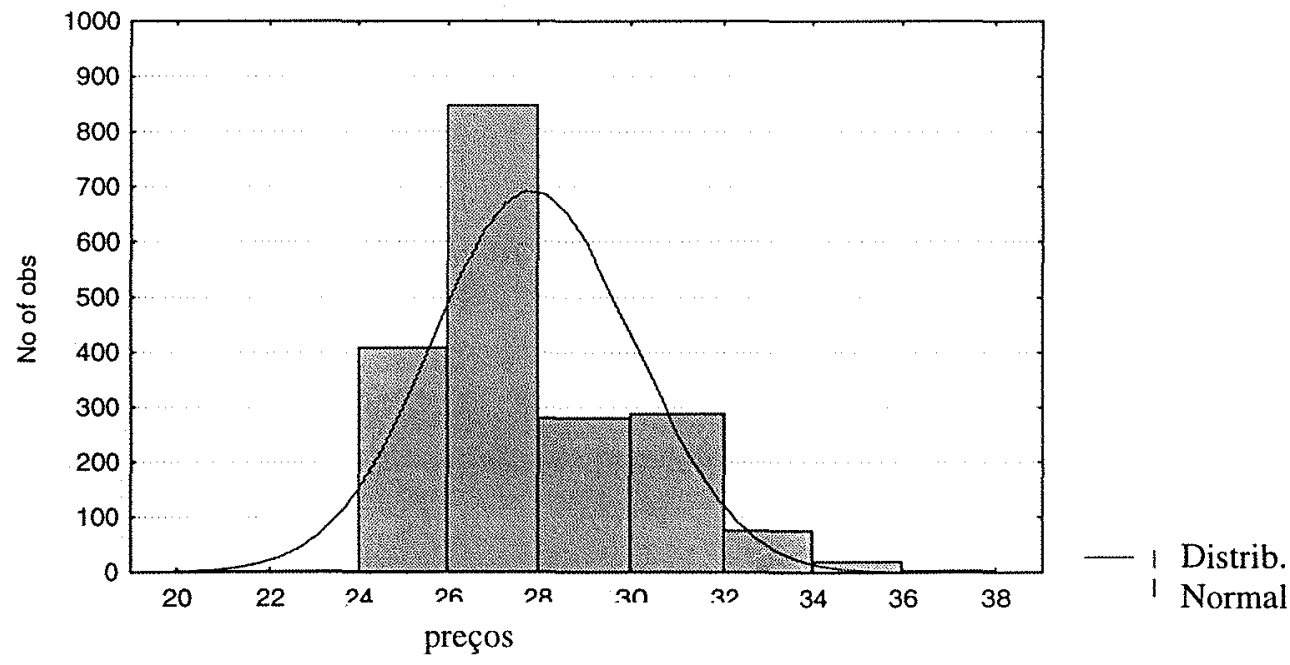

Figura 14. Teste de Lilliefors para Presidente Prudente (1).

Fonte: CEPEA, 1998; Estatística. 
ARAC 2

$K-S d=.09636, p<.01$; Lilliefors $p<.01$

Shapiro-Wilk $W=.98634, p<.0000$

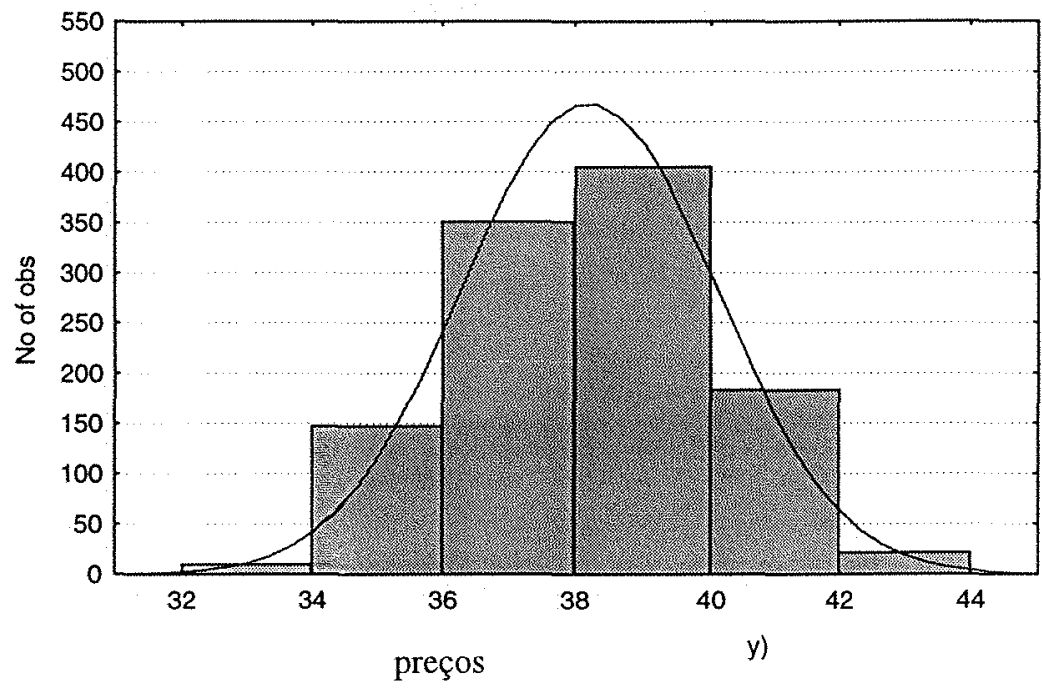

Distrib.

Normal

Figura 15. Teste de Lilliefors para Araçatuba (2).

Fonte: CEPEA, 1999; Estatística.

SJRP_2

$K-S d=.08805, p<.01$; Lilliefors $p<.01$

Shapiro-Wilk $W=.98558, p<.0000$

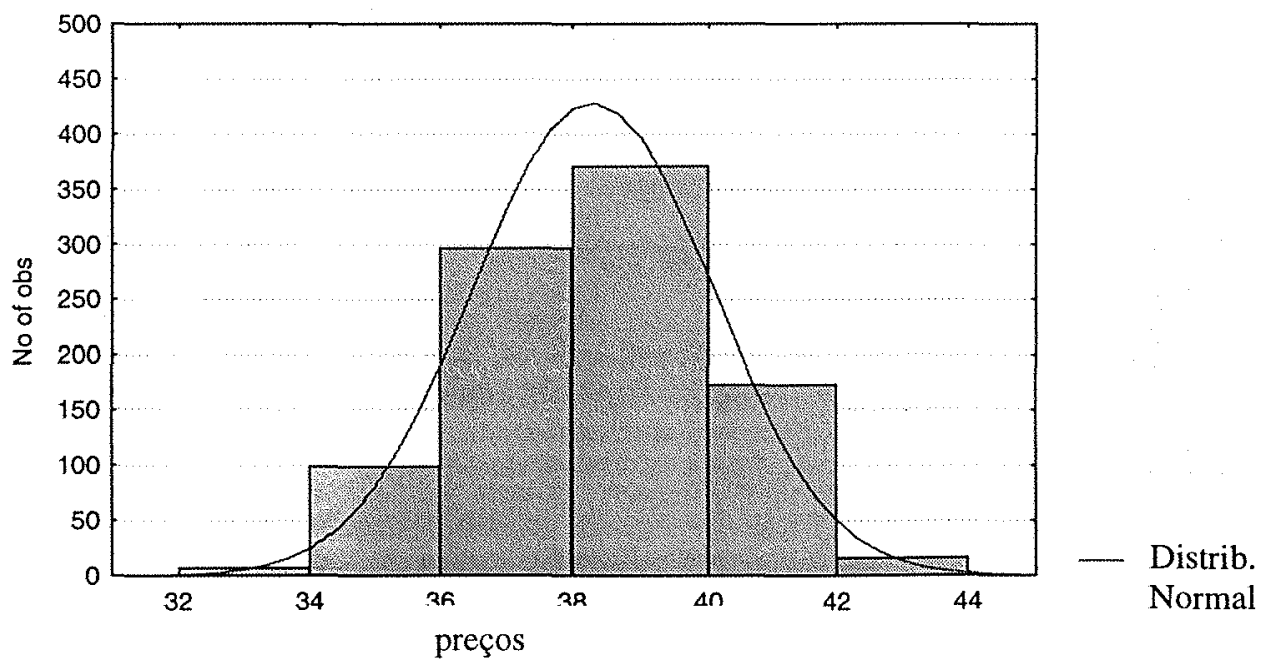

Figura 16. Teste de Lilliefors para S.J. do Rio Preto (2).

Fonte: CEPEA, 1999; Estatística. 
Gráfico de Caixa

\begin{tabular}{|c|c|c|}
\hline Histograma & $\#$ & Gráfico de Caixa \\
\hline $39+\star$ & 1 & 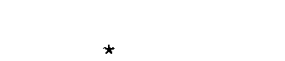 \\
\hline$\cdot *$ & 2 & 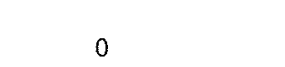 \\
\hline.$^{*}$ & 30 & 0 \\
\hline $33+* * * * *$ & 149 & 0 \\
\hline 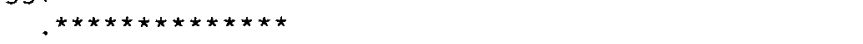 & 443 & 1 \\
\hline 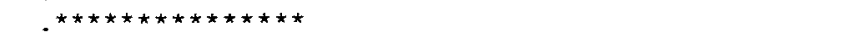 & 502 & +--+--+ \\
\hline 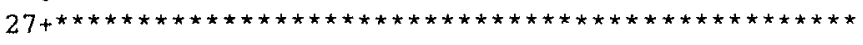 & 1600 & $*-\cdots--*$ \\
\hline . & 380 & 1 \\
\hline.$\star$ & 3 & 0 \\
\hline $21+^{\star}$ & 1 & 0 \\
\hline
\end{tabular}

Figura 17. Gráfico de Caixa para São José do Rio Preto (1).

Fonte: CEPEA, 1998; SAS.

\begin{tabular}{|c|c|c|c|}
\hline Histograma & \# & Gráfico de & Caixa \\
\hline $36.25 t^{\star}$ & 1 & & 0 \\
\hline . & & & \\
\hline * & 4 & & | \\
\hline * & 1 & & \\
\hline$* * *$ & 9 & & \\
\hline.$^{\star}$ & 3 & & \\
\hline$* \star \star *$ & 12 & & \\
\hline 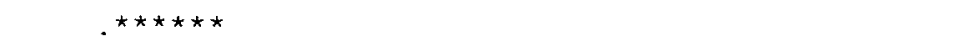 & 22 & & \\
\hline 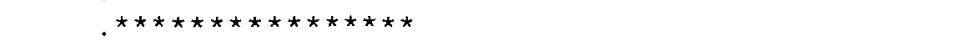 & 64 & & \\
\hline 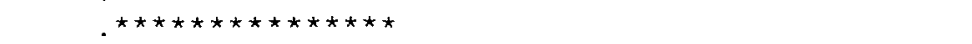 & 60 & & \\
\hline 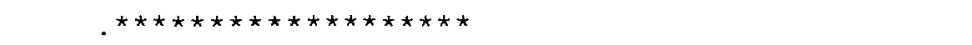 & 75 & & \\
\hline 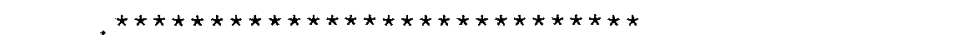 & 109 & & 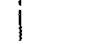 \\
\hline 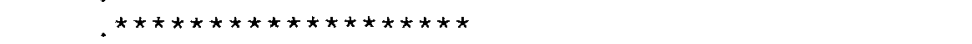 & 74 & +- & ---+ \\
\hline 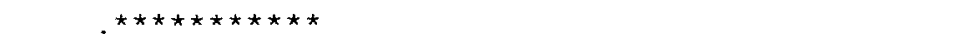 & 44 & | & 1 \\
\hline 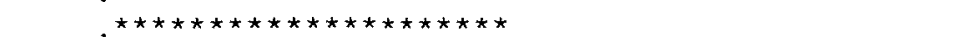 & 84 & & \\
\hline 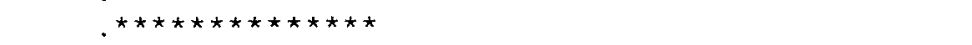 & 54 & & \\
\hline 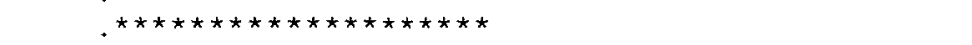 & 77 & & + \\
\hline 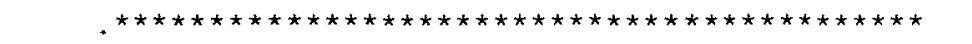 & 169 & * - & $---{ }_{-*}^{*}$ \\
\hline 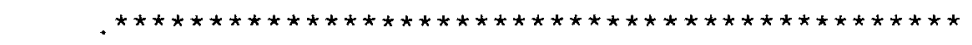 & 180 & 1 & \\
\hline 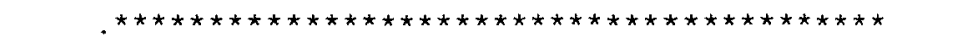 & 162 & & ---+ \\
\hline 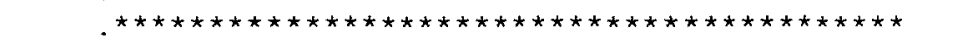 & 166 & & | \\
\hline 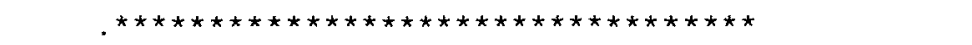 & 136 & & \\
\hline 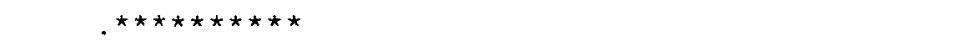 & 39 & & \\
\hline $24.75+\star$ & 2 & & 1 \\
\hline * pode representar até 4 observações & & & \\
\hline
\end{tabular}

Figura 18. Gráfico de Caixa para Bauru/Marília (1).

Fonte: CEPEA, 1998; SAS. 


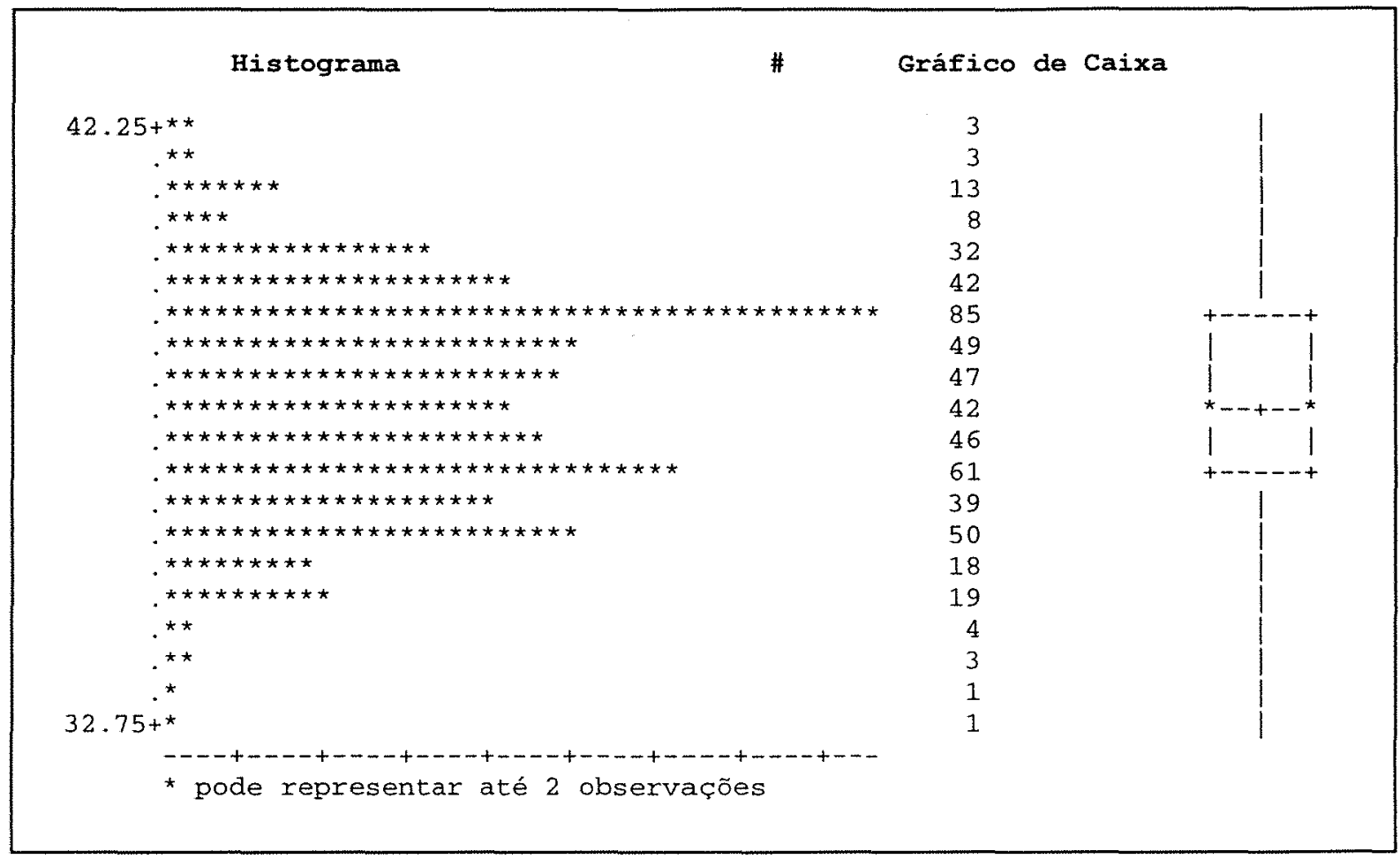

Figura 19. Gráfico de Caixa para Presidente Prudente (2). Fonte: CEPEA, 1999; SAS. 
Normal Plot

Normal Probability Plot

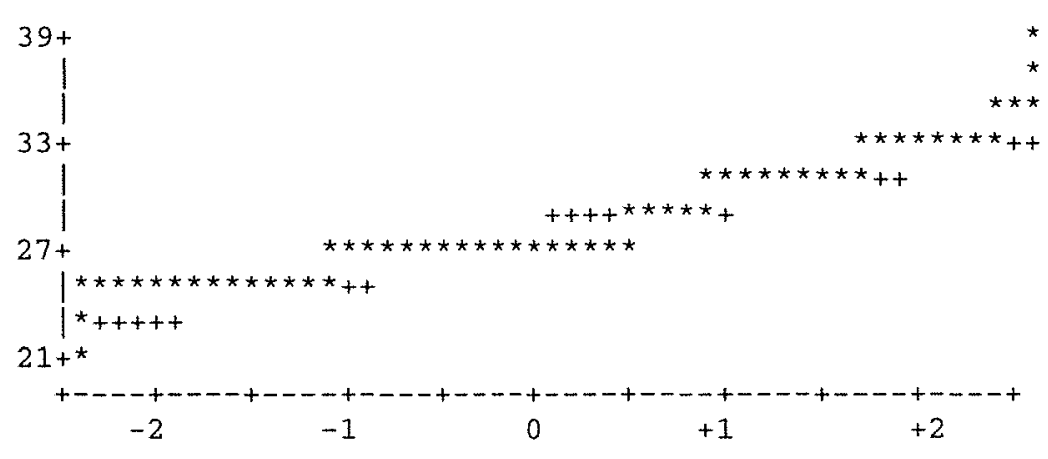

Figura 20. Normal Plot para São José do Rio Preto (1).

Fonte: CEPEA, 1998; SAS.

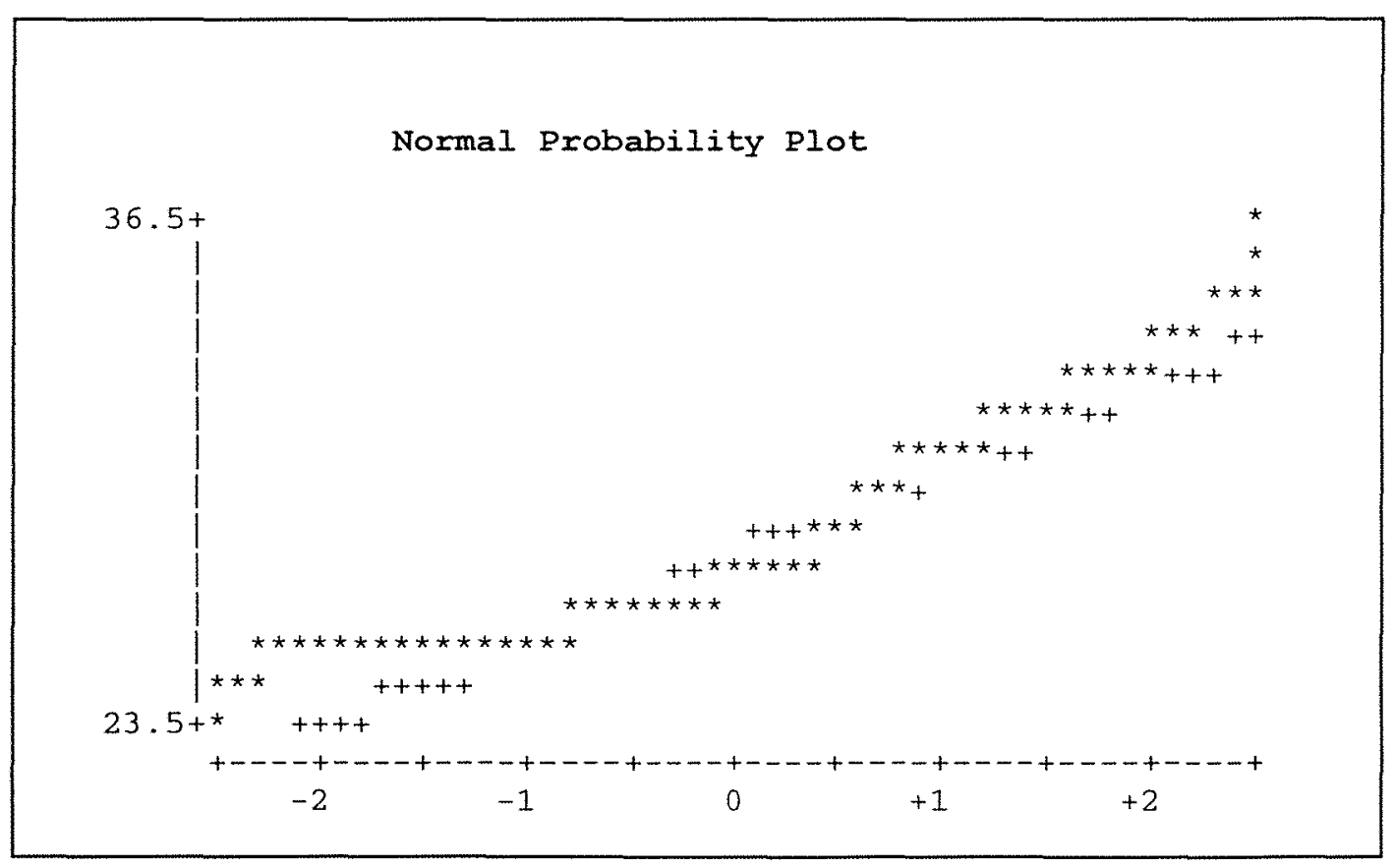

Figura 21. Normal Plot para Presidente Prudente (1). Fonte: CEPEA, 1998; SAS. 


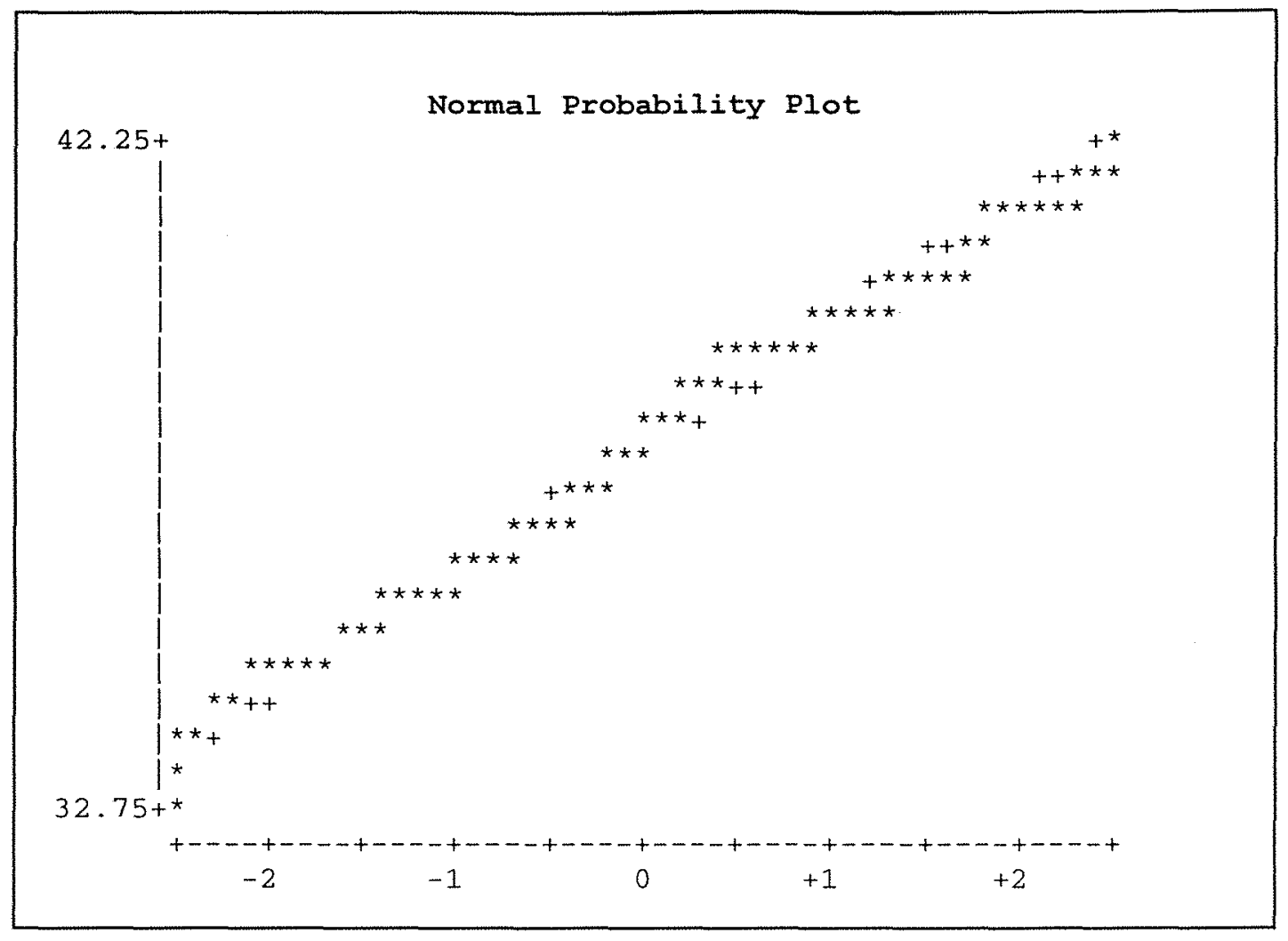

Figura 22. Normal Plot para Presidente Prudente (2).

Fonte: CEPEA, 1999; SAS.

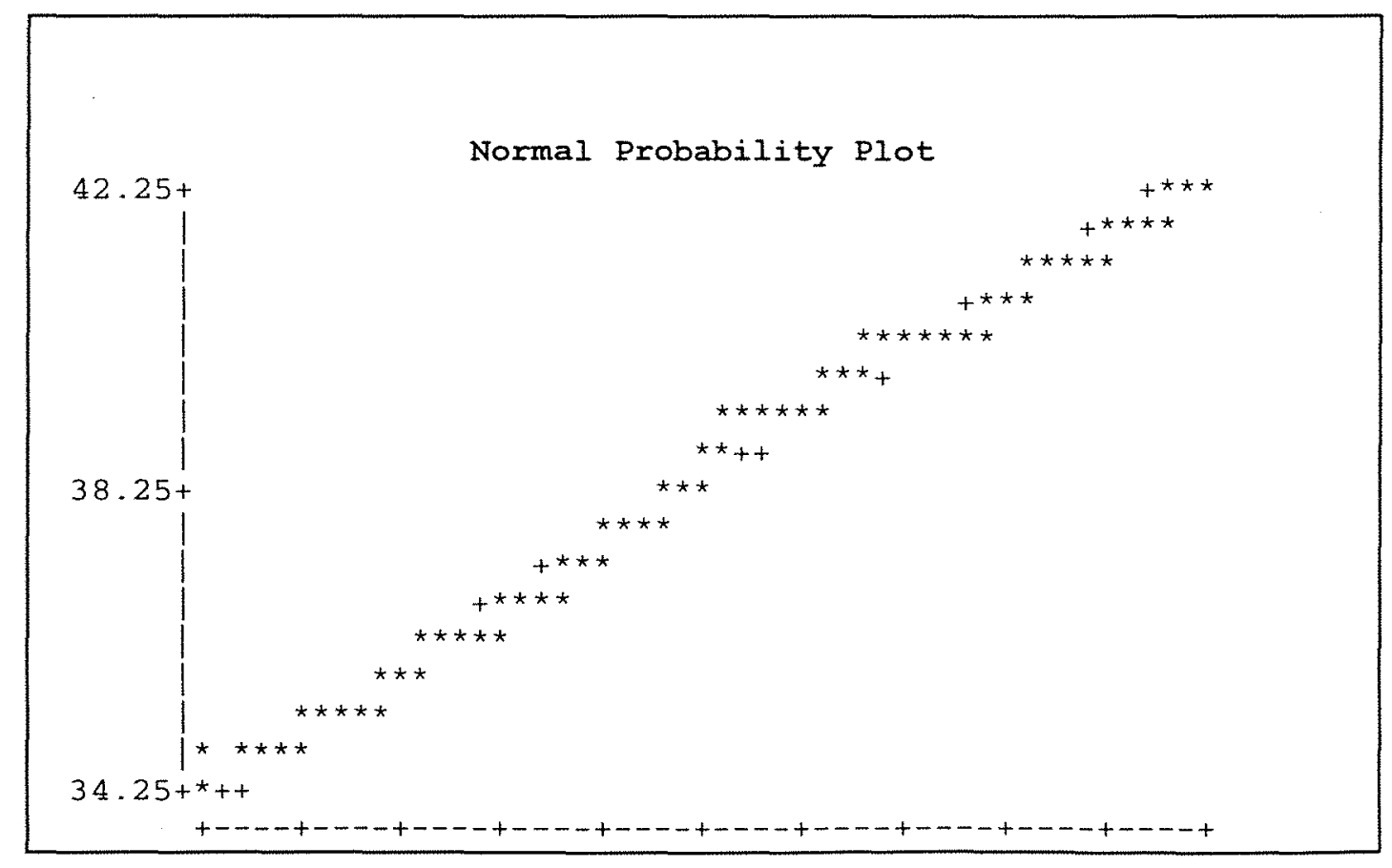

Figura 23. Normal Plot para Bauru/Marília (2).

Fonte: CEPEA, 1999; SAS. 


\section{REFERÊNCIAS BIBLIOGRÁFICAS}

BOX, G. E. P.; COX, D. R. An analysis of transformations. Journal of the Royal Statistical Society, B, v.26, p.211-252, 1964.

CAMPOS, H. de. Estatística Experimental não-paramétrica. 4. ed. Piracicaba: ESALQ, 1983. cap.2, p.38-54.

CARLSON, A.J. Are prices expectations normally distributed ? Journal of the American Statistical Association, v.70, p.749-754, 1975.

FRICK, O. Mercado Futuro de Boi Gordo em Nova Versão. Preços Agrícolas. Piracicaba :FEALQ, (109), p.8-9, 1995.

HOFFMANN, R. Estatística para Economistas. São Paulo:Pioneira,1991.426p.

IEMMA, A. F. Estatística Descritiva. Piracicaba: $\varphi \sigma \rho$ Publicações, 1992.182p.

LILLIEFORS, H. W. On the Kolmogorov-Smirnov test for normality with mean and variance unknown. The Journal of the American Statistical Association, v.62, p.399-402,1967.

MANDELBROT, B. The variation of certain speculative prices. The journal of Business, v.36, p.394-419, 1963.

MANDELBROT, B. The variation of some others speculative prices. The journal of Business, v.40, p.303-413, 1967. 
MARQUES, P.V. ; AGUIAR, D.R.A. Comercialização de Produtos Agrícolas. São Paulo: EDUSP, 1993. 295p.

PINO, F.A. Estimação L1 em modelos ARMA. São Paulo, 1990. 97p. Dissertação de Doutoramento em Estatística. Instituto de Matemática e Estatística da Universidade de São Paulo.

PINO, F.A. et al. Levantamentos de Preços por Amostragem: mercado atacadista de produtos agrícolas na Cidade de São Paulo. Agricultura em São Paulo, São Paulo, v.47, t.2, p.1-19,2000.

SCHOUCHANA, F. Introdução aos Mercados Futuros e de Opções Agropecuários. São Paulo : BM\&F, 1997.

SCHLOTZHAUER, S.D.; Littell, R. C. SAS System for Elementary Statistical Analysis. 2.ed. Cary, NC: SAS Institute Inc., 1997.

SHAPIRO, S.S. How to test normality and other distributional assumptions. 2.ed. United States of America: American Society for Quality Control, 1990. cap.3, p.2126; cap.4, p.35-39.

SHAPIRO, S. S.; GROSS, A.J. Statistical Modeling Techniques. New York: Marcel Dekker, 1981. cap.6, p.225-267.

SHAPIRO, S. S.; WILK, M. B. An analysis of variance test for normality (complete samples) Biometrics, v.52, p.591-611, 1965.

SIEGEL, S. Estatística Não - Paramétrica. São Paulo: McGraw-Hill do Brasil, 1975. $350 \mathrm{p}$.

SILVER, M. Estatística para Administradores. 2.ed. Trad. de S. Vieira; J. E. Corrente. São Paulo: Editora Atlas S.A, 2000. 458p. 
SNEDECOR, G, W.; COCHRAN, W, G. Statistical Methods. 17.ed. United States of America :The Iowa State University Press, 1980. 507p.

STEPHENS, M. A. EDF Statistics for Goodness of Fit and Some Comparisons. Journal of the American Statistical Association, v.69, p.730-737,1974.

TRIOLA, M. F. Introdução à Estatística. 7.ed. Trad. de A. A. Farias. Rio de Janeiro: LTC, 1999. 410p.

TEIXEIRA, M.A. Mercados Futuros: Fundamentos e Características Operacionais. São Paulo: Bolsa de Mercadorias \& Futuros, 1992.

ZEN, S. de. Alguns Aspectos do Processo de Formação dos Preços da Pecuária de Corte.. Preços Agrícolas. Piracicaba :FEALQ, (86), p.4-9, 1993.

ZEN, S. de. Avaliação da Atividade da Produção de Carne e as Tendências do Mercado Nacional. Bovinocultura de corte. 3.ed. Piracicaba : FEALQ, 1999. 


\section{BIBLIOGRAFIA RECOMENDADA}

BARTLETT, M. S. The use of transformations. Biometrics, v.3, p.39-52, 1947.

COCHRAN, W.G. The $\chi^{2}$ Test of Goodness of Fit. Annals of Mathematical Statistics, v.23,p.315-345, 1952.

DAHIYA,C.R.; GURLAND, J. How many classes in the Pearson Chi-Square test? Journal of the American Statistical Association, v.68, p.707-712, 1973.

DIXON, W.J. and TUKEY, J.W. Approximate Behavior of the Distribution of Winsorized t (Trimming/Winsorization 2).Technometrics, v.10, p.83-98,1968.

DYER, A.R. Comparisons of tests for normality with a cautionary note. Biometrika,v.61, p.185-189, 1974.

FRIGGE, M., HOAGLIN, D.C., and IGLEWICZ, B. Some Implementations of the Boxplot. The American Statistician, v.43, p.50-54,1989.

SILVEIRA, P. Jr; MACHADO, A. A.; ZONTA, E. P.; SILVA, J. B. da. Curso de Estatística. Pelotas: Editora Universitária, 1989.135p.

HAMPEL, F.R. The Influence Curve and Its Role in Robust Estimation. Journal of the American Statistical Association, v.69, p.383-393, 1974.

MANN, P.S. Statistics for Business and Economics. United States of America: John Wiley \& Sons,Inc.1995. 879p. 
MASSEY, F.J. The Kolmogorov-Smirnov Test for Goodness of fit. The Journal of the American Statistical Association, v.46, p.68-78, 1951.

MATOS, O.C. Econometria Básica.São Paulo : Atlas S.A.,1995.244p.

ROCHA, M.V. A Escolha da média. Revista Brasileira de Estatística, n.147, p.319335, 1976.

ROYSTON, J.P. An Extension of Shapiro and Wilk's W Test for Normality to Large Samples. Applied Statistics, v.31, p.115-124, 1982.

SPIEGEL, R. M. Theory and Problems of Statistics. In Coleção Schaum. United States of America: Mcgraw-Hill Book, 1961.359p.

STATSOFT, Inc. STATISTICA for Windows.(Computer program manual) Tulsa, OK: StatSoft, Inc, 1999.

STEEL, R.G.D.;TORRIE,J.H. Principles and Procedures of Statistics. United States of America: Mcgraw-Hill Book, 1960. 481p.

TERRELL, G.R. and SCOTT, D.W. Oversmoothed Nonparametric Density Estimates. Journal of the American Statistical Association, v.80, p.209-214,1985.

TOLEDO, G.L.; OVALLE, I.I. Estatística Básica. 2.ed. São Paulo: Atlas, 1985. 459p. 